\title{
Multinational Banks and Supranational Supervision*
}

\author{
Giacomo Calzolari ${ }^{\dagger}$ Jean-Edouard Colliard ${ }^{\ddagger}$ Gyongyi Lóránth ${ }^{\S}$
}

April 12, 2018

\begin{abstract}
Supervision of multinational banks (MNBs) by national supervisors suffers from coordination failures. We show that supranational supervision solves this problem, and decreases the expected costs of a MNB's default, taking its organizational structure as given. However, the MNB strategically adjusts its structure to the new supervisory framework. It converts its subsidiary into a branch, or conversely, with a view to reducing supervisory monitoring. We identify the cases in which this endogenous reaction leads to unintended consequences, such as higher costs to the deposit insurance fund, lower welfare, or closure of the MNB's foreign unit. Current reforms of MNB supervision should thus take into account that MNBs adapt their organizational structures to changes in supervision.
\end{abstract}

Keywords: Cross-border banks, Multinational banks, Supervision, Monitoring, Regulation, Banking Union.

JEL classification: L51, F23, G21, G28.

${ }^{*}$ This is a substantial revision of a previous working paper (CEPR DP11326). Financial support from the Investissements d'Avenir Labex (ANR-11-IDEX-0003/Labex Ecodec/ANR-11-LABX-0047) is gratefully acknowledged. We are grateful to Francesca Barbiero, Consuelo Silva Buston, Olivier de Bandt, Mark Carey, Xavier Freixas, Denis Gromb, Alexander Guembel, Anastasia Kartasheva, Matthias Lé, Thomas Mosk, Enrico Perotti, Eva Schliephake, Guillaume Vuillemey, Wolf Wagner, participants at the ACPR - Banque de France conference on Monitoring Large and Complex Banks, the 2017 EFA Meetings, the CEPR Conference on Financial Intermediaries and the Real Economy, the 2016 FDIC/JFSR Bank Research Conference, the SUERF/Bundesbank Conference on the SSM at 1, Barcelona GSE Summer Forum on Financial Intermediation and Risk, the II IWH FIN FIRE Workshop, the Santiago Finance Workshop 2016, BCBS-BIS Workshop 2017 and seminar audiences at HEC Paris, University of Bologna, University Bicocca Milan, University of Bristol and Collegio Carlo Alberto, for helpful comments and suggestions.

${ }^{\dagger}$ Department of Economics, University of Bologna, and CEPR, Piazza Scaravilli 2, 40126, Bologna, Italy. Phone: +39 0512098489. E-mail: giacomo.calzolari@unibo.it

${ }^{\ddagger}$ Department of Finance, HEC Paris, 1 rue de la Libération, 78351 Jouy-en-Josas, France. Phone: +33 1396772 90. E-mail: colliard@hec.fr .

${ }^{\S}$ Faculty of Business, Economics and Statistics and CEPR, University of Vienna, Bruenner Strasse 72, 1210, Vienna, Austria. Tel: +431427738 051. E-mail: gyoengyi.loranth@univie.ac.at. 


\section{Introduction}

Multinational banks (MNBs) operate both branches and subsidiaries in foreign countries. While branches are primarily supervised by the same authority as their parent bank, foreign subsidiaries are supervised by the host-country authorities, so that MNBs face a multiplicity of national authorities. For example, Dexia was supervised by the authorities of Belgium, France, Luxembourg and the Netherlands, and yet suffered a catastrophic failure which led to a 6 bln EUR bail-out in 2011 . Failures of this type raise questions about possible coordination issues among national supervisors. ${ }^{1}$ Accordingly, the supervision of multinational banks has been a central part of the policy debate since the financial crisis. ${ }^{2}$ In 2014, the Euro area introduced a new supervisor, the Single Supervisory Mechanism (SSM), in an effort to centralize the supervision of the area's largest banks. Importantly, MNBs are adjusting their structure to this change. For instance, Nordea converted its subsidiaries in Denmark, Finland, and Norway into branches in January 2017. At the end of 2017, the bank announced a plan to move its headquarters from Sweden to Finland. As Finland is part of the Euro area, this move ultimately transfers supervisory responsibility to the SSM. ${ }^{3}$

Despite the intense policy debate on this important issue, there is little theory to guide policy makers on how to organize the supervision of multinational banks. We build a model in which centralizing supervision solves coordination problems and decreases the public costs of a MNB's failure, keeping the organizational structure fixed. However, the MNB endogenously reacts to the new supervisory arrangements by adjusting its structure, for instance by transforming a subsidiary into a branch, or by closing the foreign unit altogether. Due to this endogenous reaction, we show that centralizing supervision ultimately leads to less supervisory monitoring, and characterize the conditions under which welfare decreases as a result. More generally, our model shows that reforms of MNB supervision should be discussed in a framework in which an MNB's organizational structure is not fixed but is an equilibrium outcome.

Our model relies on two main ingredients. First, a MNB, incorporated in a "home" country,

\footnotetext{
${ }^{1}$ See Claessens and Van Horen (2013) for a recent review of the literature on cross-border banking, and Allen et al. (2011) for a discussion of the policy issues. Beck, Todorov, and Wagner (2013) provide empirical evidence on the shortcomings of cross-border supervision in Europe.

${ }^{2}$ See, for example, the Financial Stability Board 2011 document on "Global adherence to regulatory and supervisory standards on international cooperation and information exchange," the 10 December 2012 joint paper by the Federal Deposit Insurance Corporation and the Bank of England, and Schoenmaker and Huttl (2015).

${ }^{3}$ More generally, the ECB's report on the E.U. structural financial indicators shows that Euro area countries had 550 branches and 310 subsidiaries from other E.U. countries in 2012, against 552 branches and 232 subsidiaries in 2016 (https://www.ecb.europa.eu/press/pr/date/2017/html/ecb.pr170530.en.html). This "branchification" process seems at odds with a trend towards using more subsidiaries at the global level (see "The globalisation of banking: How is regulation affecting global banks?", BBVA Research, 8 August 2016).
} 


\begin{tabular}{lcc}
\hline \hline & Subsidiary & Branch \\
\hline $\begin{array}{l}\text { Deposit insurer of the home unit } \\
\text { Deposit insurer of the foreign unit }\end{array}$ & $\begin{array}{c}\text { Home } \\
\text { Foreign }\end{array}$ & $\begin{array}{c}\text { Home } \\
\text { Home }\end{array}$ \\
\hline & & \\
\hline $\begin{array}{l}\text { Supervisor of the home unit } \\
\text { Supervisor of the foreign unit }\end{array}$ & Home & Home \\
& & Home \\
$\begin{array}{l}\text { Home unit responsible for foreign unit's liabilities } \\
\text { Foreign unit responsible for home unit's liabilities }\end{array}$ & No & Yes \\
& & Yes \\
\hline \hline
\end{tabular}

Table 1: Branches and subsidiaries.

chooses its organizational structure in a "foreign" country, namely whether to operate a subsidiary, a branch, or no foreign unit at all, depending on how supervision is organized. Second, different bank supervisors (home, foreign, and supranational) decide whether to monitor the bank, depending on the MNB's organizational structure. Both ingredients rely on institutional differences between subsidiaries and branches, which we now explain (see Table 1 for a summary).

Subsidiaries are foreign incorporated entities protected by limited liability. Should the subsidiary fail, foreign depositors have no claim on the assets of the home unit. If the subsidiary survives but the home unit fails, foreign depositors have priority over the subsidiary's assets, but the residual assets can be used to repay depositors of the home unit. Deposits are insured in our model. Any loss suffered by the subsidiary's depositors are compensated by the foreign deposit insurance fund, while losses of home depositors are compensated by the home deposit insurance fund. In contrast to subsidiaries, branches share their liabilities and assets with the home unit, so that the depositors of the parent bank and its branch have equal claims to the assets of both units. Depositors in both countries are covered by the home deposit insurance fund. ${ }^{4}$

In the model, costly monitoring allows the supervisor to detect poorly performing assets and

\footnotetext{
${ }^{4}$ The Icelandic crisis showed how real the differences in deposit insurance coverage between branches and subsidiaries could be in crisis periods. Two Icelandic banks, Landsbanki and Kaupthing, operated in the U.K. as a branch (named Icesave) and as a subsidiary (Kaupthing UK), respectively. When Landsbanki (and with it Icesave) failed, U.K. depositors lost their savings because the Icelandic Deposit Guarantee Scheme could not cope with the large amount of deposit guarantees. Kaupthing depositors, however, were insured by the U.K.'s Deposit Insurance Scheme, and were fully repaid.
} 
steer the bank towards safer activities, thereby reducing the risk of failure and the costs to the deposit insurer. ${ }^{5}$ The MNB's organizational structure affects which supervisor oversees the foreign unit. Under national supervision, a foreign subsidiary is supervised by the foreign supervisor, whose objective is to minimize losses to the foreign deposit insurance fund. Instead, a foreign branch is supervised by the home supervisor, who wants to minimize the losses to the home deposit insurance fund, which is liable for both units. Under supranational supervision, a single supervisor monitors both units of the MNB, irrespective of the MNB's structure, and aims at minimizing the losses to both deposit insurance funds.

When the MNB operates a subsidiary and supervision is national, the MNB faces two supervisors. The foreign supervisor exerts a twofold supervision externality on the home supervisor. First, monitoring the foreign unit generates information allowing the home supervisor to monitor the home unit only when the foreign unit's assets perform poorly. We call this the monitoring effect. Second, by making the foreign unit's assets safer, supervision lowers the subsidiary's profits. Since these profits can be used to offset losses in the home unit, supervision of the foreign unit increases the expected losses of the home deposit insurance fund. We call this the intervention effect. ${ }^{6}$ If the MNB operates a branch instead, the home supervisor supervises both units and internalizes these two effects.

Understanding the externality exerted by the foreign supervisor on the home supervisor allows us to predict the consequences of introducing a supranational supervisor responsible for both units, and thus internalizing the externality. ${ }^{7}$ When the monitoring effect outweighs the intervention effect, supranational supervision leads to more monitoring of the subsidiary than national supervision, while the opposite obtains when the intervention effect dominates. Monitoring of branches is not affected by supranational supervision, as there is no externality in that case.

The next step is to understand how supranational supervision changes the MNB's choice of organizational structure. When the monitoring effect dominates, supranational supervision leads to more monitoring of subsidiaries, hence lower profit under this structure, which pushes the MNB to switch to a branch structure, or even to exit foreign operations altogether. When the intervention

\footnotetext{
${ }^{5}$ See Eisenbach, Lucca, and Townsend (2016) for a general theoretical treatment of bank supervision.

${ }^{6} \mathrm{~A}$ recent illustration of this situation is given by the Greek crisis: the supervisors of Greek banks' subsidiaries in Romania and Bulgaria considered liquidating them. This would have worsened the situation of their parent banks, but this externality was not taken into account by the subsidiaries' supervisors. The ECB had to extend credit lines to these subsidiaries to avoid this outcome. See "ECB puts in place secret credit li*nes with Bulgaria and Romania", Financial Times Online, July 16, 2015.

${ }^{7}$ Given the limited liability of the parent bank towards its subsidiary, and that foreign depositors have priority over home depositors in accessing the foreign unit's assets, the home supervisor does not exert any externality on the foreign supervisor in the model.
} 
effect dominates instead, supranational supervision leads to less monitoring of subsidiaries, hence higher profit under this structure, thus pushing the MNB to switch to a subsidiary structure, or even to open a new subsidiary abroad.

Importantly, in all cases the MNB's reaction always goes towards reducing supervisory monitoring. For instance, when supranational supervision leads to more monitoring of subsidiaries, the MNB switches to a branch structure, under which the supervisor optimally chooses to monitor less. As a result, there is always (weakly) less monitoring of the MNB under supranational supervision than under national supervision.

This observation is important to understand the impact of supranational supervision on welfare, as measured by the sum of the bank's profit and the costs to the public sector (deposit insurance losses and monitoring costs). We show four main results:

(i) If supranational supervision does not affect the bank's organizational structure, it always reduces the costs to the public sector (not necessarily total welfare). This result reflects the gains from coordinating supervision of the MNB's units, holding its structure constant.

(ii) When the MNB adjusts its organizational structure to supranational supervision, converting a subsidiary into a branch is associated with a welfare increase (despite the lower monitoring), whereas converting a branch into a subsidiary is associated with a welfare decrease. In the latter case, national supervision is a superior arrangement relative to supranational supervision because it acts as a commitment to being tough with a subsidiary, and discourages the bank from using such a structure.

(iii) Unless public funds are very costly, when supranational supervision leads the MNB to open a foreign unit the impact on welfare is positive, whereas if the MNB closes its foreign unit the impact is negative. In the latter case, national supervision acts as a commitment to being lenient with a subsidiary, and encourages the MNB to operate abroad.

(iv) Finally, any change in organizational structure leads to a clear-cut redistribution of costs between the deposit insurers of the two countries: by definition, when a subsidiary is opened this increases the burden on the foreign deposit insurer, whereas when it is closed or converted into a branch the entire burden falls on the home deposit insurer.

Our theory also has empirical implications on the effects of supranational supervision, such as the introduction of the SSM. First, we predict that after such a change, foreign units that switch from a subsidiary structure to a branch structure should be less profitable, whereas foreign units that switch from a branch structure to a subsidiary structure should be more profitable. In both 
cases, monitoring should decrease. Second, we have predictions on whether a MNB will transform a subsidiary into a branch or conversely, depending on the supervisory quality of both the home and host countries. Third, we show how supervisory quality in both countries determines whether a MNB reacts to supranational supervision by closing down a foreign unit or opening a new one. More generally, our analysis suggests looking at the effects of supervision at the bank unit level and not only at the banking group level, and that these effects should be interacted with both home country and host country characteristics.

Finally, we consider several extensions of the model and check its robustness. First, we consider alternative liability structures for the MNB, such as ring-fencing part of a subsidiary's assets, or a commitment from the parent bank to rescue a failing subsidiary. Second, we assume that depositors are not fully insured and demand higher deposit rates in compensation for the losses they have to bear upon failure of the MNB. We discuss how welfare could be maximized with risk-based insurance premia that should depend on the MNB's organizational structure and on the supervisors' expected monitoring decisions.

Our paper builds on two strands of the literature. First, several papers study frictions and conflicts of objectives between national regulators. Externalities lead independent national regulators to choose suboptimal regulatory standards, in the form of too low capital requirements (Dalen and Olsen (2003), Dell'Ariccia and Marquez (2006)), too lax intervention thresholds (Acharya (2003)), or too coarse information sharing (Holthausen and Rønde (2004)). Several papers provide empirical evidence of the divergence of objectives between bank supervisors, both in the U.S. (Agarwal et al. (2014) and Rezende (2011)) and in the E.U. (Beck, Todorov, and Wagner (2013)).

Second, there is a literature looking at the endogenous choice of organizational structure of financial intermediaries based on the different liability structures between branches and subsidiaries (Kahn and Winton (2004), Dell'Ariccia and Marquez (2010), Luciano and Wihlborg (2018)). None of these papers consider supervision as a factor that could drive the choice between branches and subsidiaries. Harr and Rønde (2004) and Loranth and Morrison (2007) study optimal capital regulation and Calzolari and Loranth (2011) analyze optimal closure policies for branches and subsidiaries and their impact on the choice of organizational structure by the bank. ${ }^{8}$ Focarelli and Pozzolo (2005) and Cerutti, Dell'Ariccia, and Martinez Peria (2007) empirically investigate the determinants of MNBs' organizational choice.

We combine these two strands of the literature in a model in which supervisory treatment and

\footnotetext{
${ }^{8}$ Calzolari and Loranth (2003) provide an overview of the issues in multinational bank supervision.
} 
frictions in supervision are key drivers of the choice of organizational structure by the MNB. In particular, the optimal supervisory actions depend on the bank's organizational structure and, in turn, the bank's organizational structure optimally responds to the anticipated supervisory actions. Taking these feedback effects into account, we show that the choice of the organizational structure profoundly affects the consequences of centralizing supervision. ${ }^{9}$

Our main example of supranational supervision is the Single Supervisory Mechanism. ${ }^{10}$ Hence, we also contribute to a growing literature on the possible effects of this new architecture, with a focus on MNBs and their organizational structure which is absent from prior work. Colliard (2014) compares supranational to national supervision, focusing on the trade-off between worse quality information and less biased incentives of supranational supervisors. Carletti, Dell'Ariccia, and Marquez (2016) argue that local supervisors will have lower incentives to collect information if decisions are taken by a central regulator. Beck and Wagner (2016) also study common supervision but examine the problem of different regional preferences regarding financial stability.

Finally, Bolton and Oehmke (2016) and Faia and Weder di Mauro (2016) analyze how to wind down global systematically important banks through bail-ins, and thus deal more generally with the question of how to resolve multinational banks. We differ from these papers as our focus is on ex ante incentives, in the form of monitoring and intervention, as opposed to ex post incentives that arise upon bank failure.

\section{Model}

We first set up the model and then discuss its main assumptions.

\subsection{Setup}

We consider a multinational bank (MNB) operating two symmetric, equal-sized units in two countries: the home country $h$ (where the MNB is incorporated) and the foreign country $f$. Each unit $i \in\{h, f\}$ invests locally in a portfolio of illiquid and risky projects. The quality $q \in\{g, b\}$ of the portfolio is uncertain. With probability $\theta$, it is "good" $(q=g)$ and pays out $R>1$. With

\footnotetext{
${ }^{9}$ Our paper thus adds to the study of unintended consequences of regulation in general, a theme that goes back to at least Peltzman (1976). Recent examples involving banking regulation include Aiyar, Calomiris, and Wieladek (2014), who show that tighter macroprudential requirements lead to a substitution of lending by local banks with lending by branches of foreign banks, and Horváth and Wagner (2017), who illustrate that counter-cyclical capital requirements may increase systemic risk taking.

${ }^{10}$ The mechanisms we highlight are also relevant to understand less extreme forms of supranational supervision, such as bilateral agreements between supervisors. Beck, Silva-Buston, and Wagner (2018) give evidence on such agreements and show that their existence is related to different proxies for gains from cooperation.
} 
probability $1-\theta$, it is "bad" $(q=b)$ and pays out $R$ with probability $p<1$ only, and 0 otherwise. Returns on the portfolios in the two countries are uncorrelated. ${ }^{11}$

Investments are financed by insured deposits normalized to 1 in each country. The deposit insurance fund in charge fully reimburses depositors, so that the bank offers to repay $1 .{ }^{12}$

The bank maximizes the sum of its expected profits earned in the countries of activity.

Liability structure. By default, the bank is a "standalone" bank that operates a unit in the home country only. In addition, the bank can open a foreign unit and become a MNB, using one of the following organizational structures: ${ }^{13}$

- A subsidiary. A subsidiary is an asset of the parent bank. As such, it shares liabilities for the home unit's losses, but the reverse is not true. After foreign depositors are paid out, the remaining assets in a solvent subsidiary are used against the home unit's outstanding liabilities. No such transfer is legally required from the home unit to an insolvent subsidiary. Each national supervisor supervises its local unit and deposits are insured by the local deposit insurance fund.

- A branch. The two units share liability for each other's losses. Failure occurs when the total assets of the MNB in both units fall short of total liabilities, in which case the MNB's assets are distributed pro-rata to depositors in both countries. The supervisor in the home country oversees supervision and insures depositors in both countries.

We additionally allow for operating costs $C^{S}$ (resp. $C^{B}$ ) of running a subsidiary (resp. a branch). Depending on the business model of the bank or the specificities of the foreign country, $C^{S}$ and $C^{B}$ may in general be different.

Supervision. Supervision consists of monitoring and prudential interventions. Each unit $i \in\{h, f\}$ can be monitored at a cost $c_{i}>0$, so that the supervisor learns whether the unit's assets are good or bad. The parameter $c_{i}$ measures the monitoring difficulty. Monitoring enables the supervisor to intervene in a unit with bad assets: the supervisor requires the bank to transfer its assets into a safe project, with the same expected payoff but no risk. More specifically, after intervention the asset pays $r>1$ with certainty, and $p R=r{ }^{14}$ We assume that, due to legal restrictions, no intervention is possible in a unit that was not monitored. Note that intervention

\footnotetext{
${ }^{11}$ One of the drivers of MNBs' expansion is risk diversification, which justifies uncorrelated projects. The analysis of systemic risk is beyond the scope of this paper.

${ }^{12}$ With an equivalent interpretation of our model, the bank obtains funds from lenders in the wholesale funding market who expect to be bailed out with probability one.

${ }^{13}$ In the following, we will indicate the foreign unit simply as "the subsidiary" or "the branch" depending on the organizational structure.

${ }^{14}$ This assumption allows us to precisely identify the effect and strength of supervisory interventions, as explained next. It is also in line with the evidence given in Hirtle, Kovner, and Plosser (2016) that bank supervision reduces the volatility but not the mean of banks' return on assets.
} 
reduces the bank's profit, as it reduces the risk of the bank's portfolio without affecting its mean return, and the shareholders are protected by limited liability.

Under national supervision, local supervisors take monitoring and intervention decisions. More precisely, with a subsidiary-MNB the home and the foreign supervisors choose non-cooperatively whether to monitor and intervene in the unit they supervise. With a branch-MNB or a standalone bank only the home supervisor takes such decisions.

Under supranational supervision, a supranational supervisor takes monitoring and intervention decisions over both units. She faces the same information structure and costs as national supervisors.

Each national supervisor minimizes the sum of supervision costs, losses to the national deposit insurance fund, and to the depositors. ${ }^{15}$ The supranational supervisor's objective function is an equally weighted sum of the expected payoffs that the national supervisors would obtain in the two countries. Finally, we assume that public funds, used both to pay for monitoring costs and to reimburse depositors when the bank fails, have a marginal cost of $1+\lambda$, with $\lambda>0 .{ }^{16}$

Information. In the case of two uncoordinated national supervisors, we assume that the home supervisor can make his monitoring decision conditional on the information collected in the foreign unit, if any. If there is a single supervisor, she can choose which unit to monitor first, and make her monitoring decision in the other unit conditional on the state of the first unit.

Timeline. The following timeline summarizes the environment.

$-t=0$ : The supervisory architecture is announced. The bank faces either supranational or national supervision.

- $t=1$ : The bank chooses whether to expand abroad with a subsidiary or a branch or, alternatively, to remain a stand-alone bank in the home country.

- $t=2$ : In each unit, the supervisor in charge decides whether to monitor or not.

$-t=3$ : In each unit, the supervisor can conduct a prudential intervention if he monitored in $t=2$ and the assets are bad.

- $t=4$ : Payoffs are realized. Successful assets return $R$ (resp. $r$ ) for the risky (resp. safer) project, and 0 otherwise. Depositors are repaid either by the bank, if solvent, or by the appropriate deposit insurance fund.

\footnotetext{
${ }^{15}$ Losses to depositors are always null in the baseline model, but not in the extension of Section 5.2.

${ }^{16}$ The cost of public funds measures the loss incurred in raising additional revenues to finance public spending. See Dahlby (2008) for a discussion of theoretical foundations and empirical estimates.
} 
Assumptions. To rule out trivial cases, we make two parametric assumptions:

$$
\begin{gathered}
p R>1, \\
R<2 .
\end{gathered}
$$

Condition (H1) means that bad assets still have a positive net present value, and (H2) implies that the MNB cannot repay all depositors if only one unit is successful.

Notations. We denote with $\sigma \in\{S, B, A\}$ the MNB's decision of expanding abroad with a subsidiary, with a branch, or to remain a stand-alone bank, respectively.

The decision of a supervisor in a given unit $i \in\{h, f\}$ is twofold: first, whether to monitor unit $i$, if applicable conditionally on the state of the other unit; second, whether to intervene in unit $i$. We will show below that monitoring and intervention decisions taking place in unit $i$ at $t=2$ and $t=3$ can be summarized in a single decision $d_{i}$, and that all but three possible decisions can be discarded. Decision $d_{i}=M$ (monitoring) consists in monitoring unit $i$, irrespective of what happens in the other unit, and intervene if and only if its assets are bad. Decision $d_{i}=C$ (conditional monitoring) consists in monitoring unit $i$ only if the other unit has bad assets, and intervene in unit $i$ if and only if its assets are bad. Decision $d_{i}=O$ (open) consists in never monitoring unit $i$, and thus forgoing the option of intervening in this unit.

We denote with $W_{h}\left(d_{h}, d_{f}\right), W_{f}\left(d_{f}\right)$, and $W_{b}\left(d_{h}, d_{f}\right)$ the supervisors' expected payoffs (not weighted by $1+\lambda$ ) with the subsidiary-MNB (the first two) and with the branch-MNB (the third). $W_{h}\left(d_{h}\right)$ is the home supervisor's expected payoff when the bank remains domestic. Similarly, $\Pi\left(\sigma, d_{h}, d_{f}\right)$ denotes the expected profit of an MNB with the organizational structure $\sigma \in\{S, B\}$ and $\Pi\left(A, d_{h}\right)$ the profit of a stand-alone bank in country $h$, not including the costs $C^{S}$ and $C^{B}$.

Figure 1 summarizes the tree of the game for periods 1 and 2 when supervision is national.

\subsection{Discussion}

Bank supervision. Prudential supervision comprises a range of activities intended to address unsafe practices that could jeopardize a bank's viability. ${ }^{17}$ We assume that bank supervisors aim at minimizing losses to the bank's creditors, which in our setup corresponds to minimizing losses to

\footnotetext{
${ }^{17}$ We explicitly abstract from minimum capital requirements and convertible liabilities. Although these regulatory tools may affect some of the decisions of a supervisor, they are unlikely to impact the incentives to choose one organizational form rather than another in our model.
} 


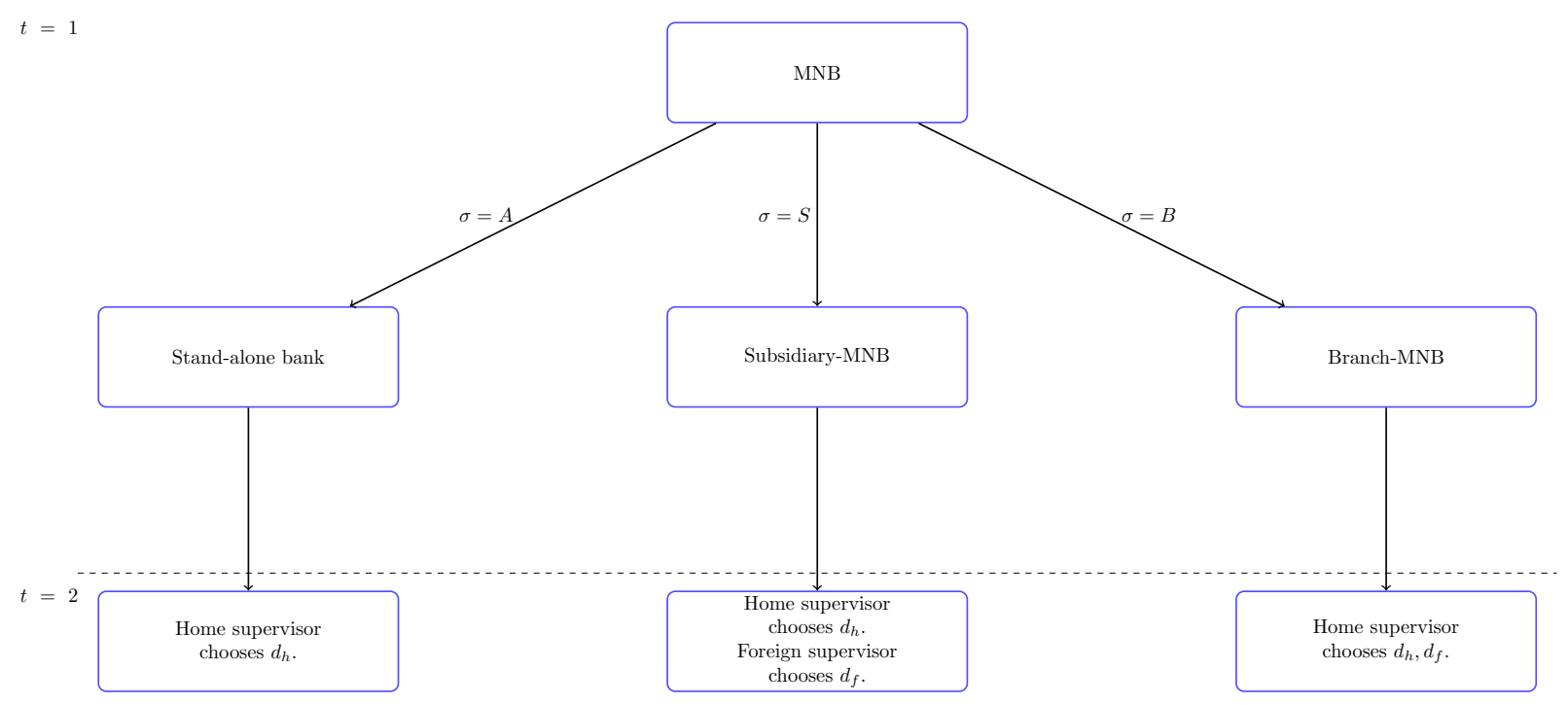

Figure 1: Periods $t=1$ and $t=2$ under national supervision.

the deposit insurance fund. ${ }^{18}$ A prominent example of a supervisor with the objective of minimizing losses to the deposit insurance fund is the Federal Deposit Insurance Corporation. More broadly, Demirguc-Kunt, Kane, and Laeven (2014) find that 57 percent of deposit insurance funds in the world have responsibilities that include minimizing losses or risk to the fund.

Organizational structures. An important element of our analysis is that the MNB can choose from three organizational structures, which define a liability structure and an allocation of supervisory responsibilities. While the liability structures we assume correspond to the definitions of a branch and a subsidiary, in practice and especially in a crisis, a MNB may not always follow these rules. We discuss this possibility in Section 5.1.

Differences between subsidiaries and branches exist beyond the liability structure and supervisory arrangements. These differences are subsumed in the parameters $C^{S}$ and $C^{B}$. For instance, being separate legal entities, subsidiaries typically have higher legal and administrative burdens and may restrict the bank's ability to reduce tax payments (Fiechter et al. (2011)), so that we would expect to have $C^{B} \leq C^{S}$. However, subsidiaries may have other advantages. For instance, Cerutti, Dell'Ariccia, and Martinez Peria (2007) find that foreign banks are more likely to enter via subsidiaries when they plan to penetrate host markets.

Allocation of Supervisory Responsibilities. Our modeling assumptions reflect real-life arrange-

\footnotetext{
${ }^{18}$ Dewatripont and Tirole (1994) have argued that since dispersed depositors may be unable to monitor a bank, the supervisor should step in and act in their interest. Indeed, in our model the supervisor acts as a perfect representative of depositors ("representation hypothesis") by assuming the control rights of debt holders.
} 
ments. Indeed, both in the E.U. and in the U.S., the competent authority for the supervision of a branch is the one where the bank is initially licensed. Subsidiaries are incorporated in the host country and are supervised locally. The main example of supranational supervision is the European SSM. Since November 2014, the European Central Bank is entrusted with the primary responsibility for supervising the most significant Euro Area banks. Our modelling of supranational supervision in the paper corresponds to this supervisory architecture.

The U.S. banking system also provides an interesting example of externalities between supervisory authorities. For instance, Wells Fargo \& Company (WFC) is a bank holding company supervised by the Federal Reserve, which operates multiple subsidiaries and branches domestically and internationally. Its primary subsidiary is Wells Fargo Bank, N.A., a national bank supervised by the Office of the Comptroller of the Currency, but WFC also operates Wells Fargo Bank, Ltd., a California State Bank supervised by the California Department of Business Oversight - Division of Financial Institutions. The supervisors of the national bank and the state bank both exert externalities on each other and on the supervisor of the bank holding company, which can be interpreted as the supranational supervisor (see Agarwal et al. (2014) for evidence of conflicts of objectives between State and Federal supervisors).

Monitoring difficulty and information. The monitoring difficulty $c_{i}$ should be thought of as related to the legal and institutional framework in country $i$, as we discuss in Section 4.1. We abstract from potential differences of expertise or cost-efficiency between national and supranational supervisors and assume they face the same cost, so as to focus the analysis on the different incentives of these two levels. Adding an informational friction for the supranational supervisor would clearly mitigate the benefit of centralized supervision, but this effect would be orthogonal to the main mechanisms we consider.

Our model assumes that information generated by monitoring the foreign unit is shared with the home supervisor. Indeed, as will become clear below, the foreign supervisor has nothing to gain by hiding information. Our assumption can thus be seen as the outcome of a simple waiting game, in which in equilibrium the foreign supervisor would take his monitoring decision as soon as he can, and the home supervisor would take his decision immediately after. ${ }^{19}$

\footnotetext{
${ }^{19}$ See, for example, Repullo (2001) and Holthausen and Rønde (2004) for models with strategic information sharing. Our analysis would also hold if information sharing between national supervisors were assumed to be impossible: in that case, there would be a clear rationale for centralizing supervision so as to allow for communication. Our model shows that such a rationale exists even without informational frictions between the two supervisors.
} 


\section{National supervisors and the multinational bank}

By choosing whether to organize as a subsidiary or a branch, the MNB effectively decides whether it faces two uncoordinated supervisors, or a single supervisor. In this Section, we study the monitoring and prudential decisions of independent national supervisors for the different structures that the MNB can adopt. We begin the analysis with the benchmark case of a standalone bank.

\subsection{Supervision of a standalone bank}

Consider the supervision of a standalone bank in country $h$, with a single supervisor and hence no friction in supervision. If the supervisor does not monitor, the deposit insurance fund suffers a loss of 1 when the risky project fails, which happens with probability $(1-\theta)(1-p)$. We thus have:

$$
W_{h}(O)=-(1-\theta)(1-p)
$$

If instead the supervisor monitors the home unit, at cost $c_{h}$, he can intervene when the assets are bad, which happens with probability $1-\theta$. Intervention makes the bank invest in a safe project. Hence, losses to the deposit insurance fund are reduced to zero and the cost is equal to the monitoring cost:

$$
W_{h}(M)=-c_{h}
$$

Comparing these two payoffs gives the supervisor's optimal decision for the stand-alone, $d_{h}^{a}$ :

$$
\begin{aligned}
d_{h}^{a} & =\left\{\begin{array}{l}
M \text { if } c_{h} \leq c^{*} \\
O \text { if } c_{h}>c^{*},
\end{array}\right. \\
\text { with } c^{*} & =(1-\theta)(1-p) .
\end{aligned}
$$

The supervisor simply compares the cost of monitoring to $c^{*}$, which can be interpreted as the value of monitoring, i.e., the lower probability of having to reimburse 1 to depositors when the unit is monitored. This value is larger when the unit is riskier ( $\theta$ is low).

\subsection{Supervision of a subsidiary-MNB}

We now consider the interaction of the two national supervisors of a subsidiary-MNB. Because foreign depositors have priority over the subsidiary's assets and the home unit has limited liability 
for the subsidiary's losses, the decision in the home unit affects neither the intervention nor the monitoring of the foreign supervisor. From the foreign supervisor's perspective, the subsidiary is equivalent to a stand-alone bank in country $f$, and the optimal decision $d_{f}^{*}$ is defined exactly like $d_{h}^{a}$ in (3), irrespective of the home supervisor's decision.

The situation is different for the home supervisor. First, if the foreign unit is monitored, the home supervisor can condition his monitoring decision on the state of the other unit. Formally, he can select a decision $d_{h} \in\{O, C, M\}$, compared to $d_{h} \in\{O, M\}$ if the foreign unit is not monitored. Second, the home supervisor can offset losses in the home unit by using the residual assets of the foreign unit, that is, the value of its assets above what is used to reimburse foreign depositors. The value of residual assets depends on the foreign supervisor's decision $d_{f}$. To see this, denote by $\rho_{q}\left(d_{f}\right)$ the expected value of residual assets when the foreign assets are of quality $q \in\{g, b\}$, and denote by $\rho\left(d_{f}\right)=\theta \rho_{g}\left(d_{f}\right)+(1-\theta) \rho_{b}\left(d_{f}\right)$ the unconditional expected value of the residual assets. We have:

$$
\begin{array}{cl}
\rho_{g}(O)=R-1 & \rho_{b}(O)=p(R-1) \\
\rho_{g}(M)=R-1 & \rho_{b}(M)=r-1 .
\end{array}
$$

Using these definitions, we can solve for the optimal decision of the home supervisor by maximizing $W_{h}\left(d_{h}, d_{f}\right)$ in $d_{h}$, both for $d_{f}=O$ and $d_{f}=M$. We obtain:

Proposition 1. The equilibrium decisions $\left(d_{h}^{*}, d_{f}^{*}\right)$ of the supervisors of a subsidiary-MNB are:

(i) The foreign supervisor chooses $d_{f}^{*}=O$ if $c_{f}>c^{*}$, in which case the home supervisor chooses $d_{h}^{*}=M$ if $c_{h} \leq c^{*}[1-\rho(O)]$, and $d_{h}^{*}=O$ otherwise.

(ii) The foreign supervisor chooses $d_{f}^{*}=M$ if $c_{f} \leq c^{*}$, in which case the home supervisor chooses $d_{h}^{*}=M$ if $c_{h} \leq c^{*}\left[1-\rho_{g}(M)\right], d_{h}^{*}=C$ if $c_{h} \in\left(c^{*}\left[1-\rho_{g}(M)\right], c^{*}\left[1-\rho_{b}(M)\right]\right]$, and $d_{h}^{*}=O$ otherwise.

Fig. 2 below illustrates the pattern of decisions in the $\left(c_{h}, c_{f}\right)$ space. It is easy to show that $c^{*}\left[1-\rho_{g}(M)\right] \leq c^{*}[1-\rho(O)] \leq c^{*}\left[1-\rho_{b}(M)\right]$, so that the positioning of the different regions in the graph is a general result. The key idea here is the following. Monitoring a standalone unit allows to avoid a cost of 1 to the deposit insurance fund with probability $(1-\theta)(1-p)=c^{*}$. In contrast, in the presence of a subsidiary, the cost to the home deposit insurance fund in case of default is not simply 1, but 1 minus the residual assets of the subsidiary. The incentives to monitor the home unit thus decrease with the value of residual assets in the foreign unit. As monitoring the foreign unit reduces the expected value of its residual assets, it also increases the incentives to monitor the 
home unit.

\subsection{Supervision of a branch-MNB}

There are three differences when we move from the subsidiary case to the branch: (i) a single supervisor now takes the decisions $\left(d_{h}, d_{f}\right)$ for both units; (ii) the assets of the home unit can be used to pay back depositors when the foreign unit defaults; (iii) both the domestic and foreign depositors are covered by the home deposit insurance. Except for the monitoring costs, the two units are entirely symmetric in the branch case. We can focus the analysis on the case $c_{h} \leq c_{f}$ and obtain the other case by symmetry. The following Proposition characterizes the optimal decisions depending on the monitoring costs of the two units:

Proposition 2. When $c_{h} \leq c_{f}$, the optimal decisions $\left(d_{h}^{b}, d_{f}^{b}\right)$ of the supervisor of a branch-MNB are:

$(M, M)$ obtains for $c_{f} \leq c^{*}\left[1-\rho_{g}(M)\right]$ and $c_{f}+c_{h} \leq 2 c^{*}[1-\rho(O)]$;

$(M, C)$ for $c_{f} \in\left(c^{*}\left[1-\rho_{g}(M)\right], c^{*}\left[1-\rho_{b}(M)\right]\right]$ and $c_{h}+(1-\theta) c_{f} \leq c^{*}[1-\rho(O)]+(1-\theta) c^{*}\left[1-\rho_{b}(O)\right]$;

$(M, O)$ for $c_{f} \geq c^{*}\left[1-\rho_{b}(M)\right]$ and $c_{h} \leq c^{*}\left[1-c^{*}-\rho(O)\right]$;

$(O, O)$ otherwise.

The solution in the case $c_{f}<c_{h}$ is obtained by inverting $c_{h}$ and $c_{f}$, as well as $d_{h}^{b}$ and $d_{f}^{b}$.

Although the complete characterization is lengthy, the intuition behind Proposition 2 is simple: When monitoring costs are low in both units, the optimum is to exert monitoring in both. When monitoring costs are both high there is no monitoring at all. If one cost is low and the other is intermediate, the "cheaper" home unit is always monitored, whereas the other unit is monitored only when home assets are bad (case $(M, C)$ ). Fig. 2 illustrates the pattern of decisions and how they compare with the subsidiary case. In particular, we observe the following:

Corollary 1. The branch structure leads to less monitoring than the subsidiary structure: (i) If the foreign unit is not monitored with a subsidiary-MNB, it is not monitored with a branch-MNB either: $d_{f}^{*}=O \Rightarrow d_{f}^{b}=O$; (ii) If neither unit is monitored with a subsidiary-MNB, they are not monitored with a branch-MNB either: $\left(d_{h}^{*}, d_{f}^{*}\right)=(O, O) \Rightarrow\left(d_{h}^{b}, d_{f}^{b}\right)=(O, O)$.

As discussed in Section 2.2, the incentives to monitor a given unit decrease in the expected amount of residual assets in the other unit. With a branch structure, losses in the foreign unit can be offset by using the residual assets of the home unit, which is not the case with a subsidiary 

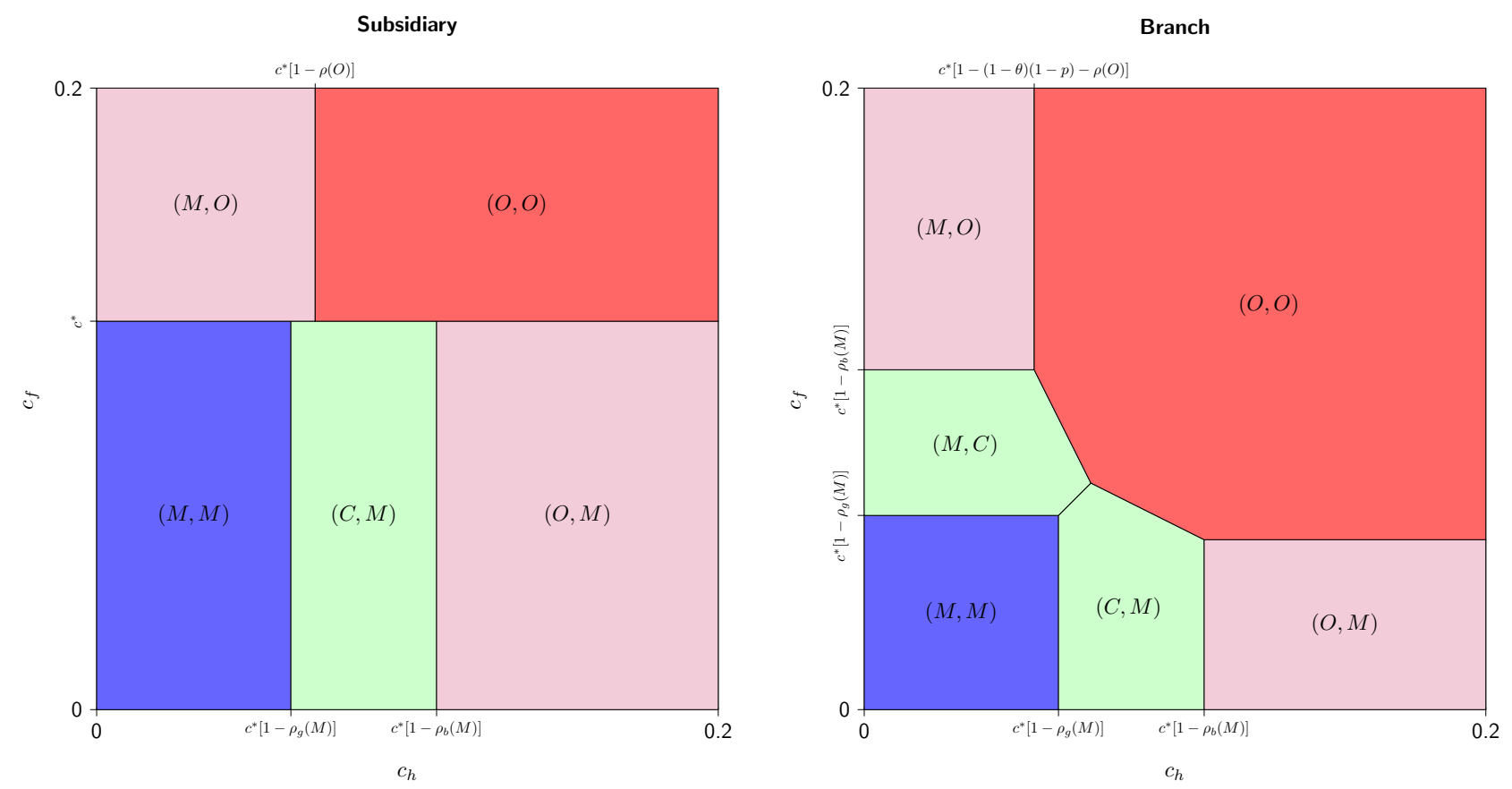

Figure 2: Equilibrium supervisory decisions under national supervision of a subsidiary and a branch, as functions of the monitoring $\operatorname{costs} c_{h}$ and $c_{f}$. The parameters are $\theta=1 / 2, p=3 / 4, R=1.5$.

structure. As a result, the incentives to monitor any unit are lower with a branch than with a subsidiary. In a sense, the branch structure is a way for the MNB to commit the value of its home assets to reimbursing losses in the foreign unit, and thus optimally generate less monitoring.

\section{Supranational supervision}

We now turn to the case of a supranational supervisor. We first solve for the supervisor's decision for a given organizational structure of the MNB. We then study the organizational structure chosen by the MNB, anticipating the decision of the supranational supervisor. Finally, we conclude this section with an analysis of the welfare impact of introducing supranational supervision.

\subsection{Impact of supranational supervision for a given organizational structure}

Proceeding by backward induction, we solve for the supervisor's decision in $t=2$ and $t=3$, for a given organizational structure chosen by the MNB in $t=1$. Recall that the supranational supervisor maximizes the joint expected payoffs of the deposit insurance funds in both countries, net of supervision costs. For the branch and the stand-alone cases, the supranational supervisor thus has the same objective function as the national supervisor, so that we only need to focus on the 
case of a subsidiary-MNB. In that case, the supranational supervisor's decision $\left(d_{h}, d_{f}\right)$ maximizes $W_{h}\left(d_{h}, d_{f}\right)+W_{f}\left(d_{f}\right)$. We denote by $\left(d_{h}^{* *}, d_{f}^{* *}\right)$ the optimal decisions.

We want to identify the cases in which the supranational supervisor's decisions $\left(d_{h}^{* *}, d_{f}^{* *}\right)$ are different from $\left(d_{h}^{*}, d_{f}^{*}\right)$, the outcome of national supervision. $\left(d_{h}^{* *}, d_{f}^{* *}\right)$ and $\left(d_{h}^{*}, d_{f}^{*}\right)$ can both take five values, so that there are 20 different possibilities to consider. This number can be substantially reduced by observing the following:

Lemma 1. National and supranational supervision in a subsidiary-MNB may lead to a different outcome only if the decision in the foreign unit is different: If $d_{f}^{*}=d_{f}^{* *}$, then $d_{h}^{*}=d_{h}^{* *}$.

Intuitively, the foreign supervisor exerts an externality on the home supervisor, while the opposite is not true. For a given decision in the foreign unit, minimizing the losses of the home deposit insurance fund is equivalent to minimizing the total losses of both funds. Hence, supranational supervision can lead to a different outcome only if it affects the supervision of the foreign unit.

To understand the impact of foreign supervision on the home unit, we can compute the difference between the best payoff attainable by the home supervisor when the foreign supervisor monitors, minus the best payoff he can achieve when the foreign supervisor does not monitor. This is what we call the supervision externality, denoted by $S E$ :

$$
S E=\max _{d_{h} \in\{O, M, C\}} W_{h}\left(d_{h}, M\right)-\max _{d_{h} \in\{O, M\}} W_{h}\left(d_{h}, O\right)
$$

To better understand the externality exerted by the foreign supervisor, we can further decompose $S E$ into two components:

$$
\begin{aligned}
S E & =\eta_{M}+\eta_{I} \\
\text { with } \eta_{M} & =\max _{d_{h} \in\{O, M, C\}} W_{h}\left(d_{h}, M\right)-\max _{d_{h} \in\{O, M\}} W_{h}\left(d_{h}, M\right) \\
\eta_{I} & =\max _{d_{h} \in\{O, M\}} W_{h}\left(d_{h}, M\right)-\max _{d_{h} \in\{O, M\}} W_{h}\left(d_{h}, O\right) .
\end{aligned}
$$

The quantity $\eta_{M}$ measures a monitoring effect: when the foreign unit is monitored, this allows the home supervisor to condition monitoring on the state of the foreign unit. This quantity is non-negatie, by definition. The quantity $\eta_{I}$ measures instead a non-positive intervention effect: monitoring the foreign unit decreases the expected value of its residual assets and negatively affects the home supervisor, as seen in Section 2.2. The sign of the supervision externality thus depends on the balance between a positive monitoring effect and a negative intervention effect. Using 
Proposition 1, we compute $\eta_{M}$ and $\eta_{I}$ explicitly:

$$
\eta_{M}= \begin{cases}0 & \text { if } c_{h} \leq c^{*}\left[1-\rho_{g}(M)\right] \\ \theta\left[c_{h}-c^{*}\left(1-\rho_{g}(M)\right)\right] & \text { if } c_{h} \in\left(c^{*}\left[1-\rho_{g}(M)\right], c^{*}[1-\rho(M)]\right] \\ (1-\theta)\left[c^{*}\left(1-\rho_{b}(M)\right)-c_{h}\right] & \text { if } c_{h} \in\left(c^{*}[1-\rho(M)], c^{*}\left[1-\rho_{b}(M)\right]\right] \\ 0 & \text { if } c_{h}>c^{*}\left[1-\rho_{b}(M)\right] .\end{cases}
$$

Intuitively, $\eta_{M}$ captures the benefit of decision $C$ over the best alternative $M$ or $O$ under national supervision. When the best alternative is $M$, decision $C$ allows to not monitor the home unit when the foreign unit has good assets. This happens with probability $\theta$, in which case the supervisor saves $c_{h}$ in monitoring costs but incurs some losses, equal to $c^{*}\left(1-\rho_{g}(M)\right)$, when the home assets are bad (the second line in (11)). Conversely, compared to $O$, decision $C$ allows to monitor the home unit when the foreign assets are bad (i.e. with probability $1-\theta$ ), which reduces expected losses by $c^{*}\left(1-\rho_{b}(M)\right)$, but costs $c_{h}$ (the third line). If the monitoring costs $c_{h}$ are sufficiently low, $C$ is always dominated by $M$; if they are sufficiently high, $C$ is dominated by $O$, and in both cases the monitoring effect is thus null (the first and fourth lines). $\eta_{I}$ is given by:

$$
\eta_{I}= \begin{cases}0 & \text { if } c_{h} \leq c^{*}[1-\rho(O)] \\ -\left(c_{h}-c^{*}[1-\rho(O)]\right) & \text { if } c_{h} \in\left(c^{*}[1-\rho(O)], c^{*}[1-\rho(M)]\right] \\ -c^{*}[\rho(O)-\rho(M)] & \text { if } c_{h}>c^{*}[1-\rho(M)] .\end{cases}
$$

To understand why $\eta_{I}$ is non-positive, notice that when the home unit fails, the home deposit insurance fund is de facto the new owner of the MNB. It benefits from the upside of the subsidiary, but the downside is absorbed by the foreign deposit insurance fund. As a result, the home supervisor prefers the subsidiary to adopt a risky strategy and is always hurt by interventions in the foreign unit. Thus, the foreign supervisor intervenes too much from the point of view of the home supervisor.

From Lemma 1 and the two effects at play, we deduce that supranational supervision can lead to a different outcome from national supervision only if the supranational supervisor monitors the foreign unit more than the foreign supervisor because the monitoring effect prevails, or if she monitors the foreign unit less than the foreign supervisor because the intervention effect prevails. The following Proposition summarizes these two cases:

Proposition 3. Supranational supervision leads to a different outcome from national supervision 
if and only if one of the following conditions holds:

(i) $c_{h}$ is such that $S E>0$ and $c_{f} \in\left[c^{*}, c^{*}+S E\right]$. Then $d_{f}^{*}=O$ and $\left(d_{h}^{* *}, d_{f}^{* *}\right)=(C, M)$.

(ii) $c_{h}$ is such that $S E<0$ and $c_{f} \in\left[c^{*}+S E, c^{*}\right]$. Then $d_{f}^{*}=M$ and $d_{f}^{* *}=O$.

The Appendix A.5 gives the exact conditions on the parameters and all possible cases.

Fig. 3 illustrates the pattern of decisions of the supranational supervisor, and the two cases of Proposition 3. The most important property is that the impact of supranational supervision depends unambiguously on $c_{f}$ : supranational supervision can lead to more monitoring of the foreign unit only when $c_{f}>c^{*}$, and to less monitoring only when $c_{f} \leq c^{*}$. The cost $c_{h}$ then determines the magnitude of the supervision externality and the optimal decision in the home unit.
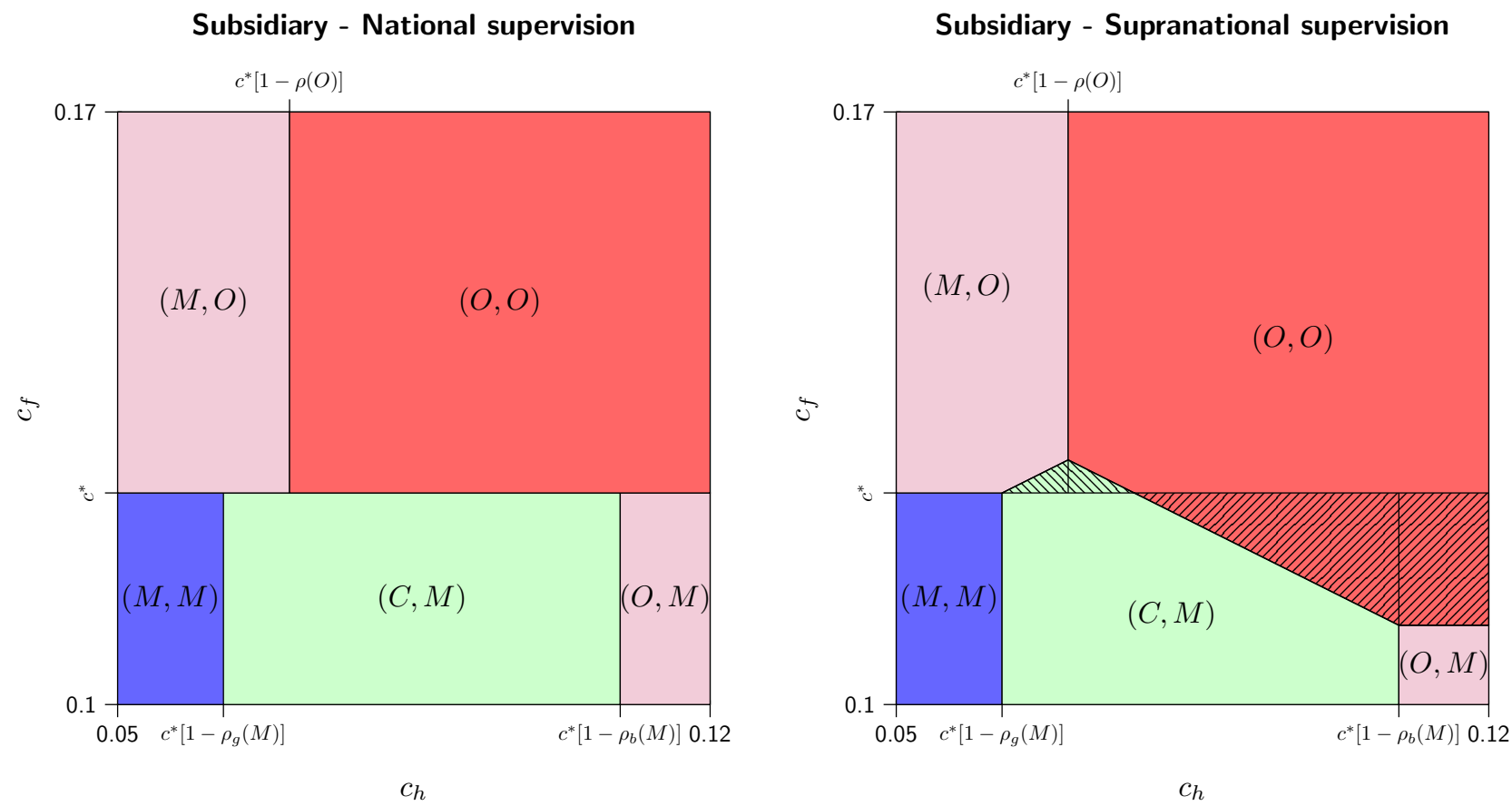

Figure 3: Equilibrium supervisory decisions under national and supranational supervision of a subsidiary, as functions of the monitoring $\operatorname{costs} c_{h}$ and $c_{f}$. The dashed regions in the right panel are those in which supranational supervision leads to more monitoring of the foreign unit (for $c_{f}>c^{*}$ ), or to less monitoring (for $c_{f}<c^{*}$ ). The parameters are $\theta=1 / 2, p=3 / 4, R=1.5$.

This Proposition has a clear implication on how supranational supervision affects the MNB's profit:

Corollary 2. Introducing a supranational supervisor leads to a (weakly) lower profit for a subsidiary$M N B$ if $c_{f}>c^{*}$, and to a (weakly) higher profit otherwise.

When $c_{f}>c^{*}$, the monitoring effect implies that the supranational supervisor exerts more 
monitoring than uncoordinated national supervisors, and thus intervenes more, so that the MNB is less profitable. Conversely, when $c_{f} \leq c^{*}$, the intervention effect dominates and the supranational supervisor intervenes less, which increases the MNB's profit.

\subsection{Impact of supranational supervision on the optimal organizational structure}

We now consider the organizational structure chosen by the bank in $t=1$, which depends on a trade-off between four different elements: (i) for given supervisory decisions, the MNB enjoys a higher implicit subsidy from deposit insurance with a subsidiary structure than with a branch structure; (ii) the branch structure leads to less monitoring than the subsidiary structure; (iii) the $\operatorname{costs} C^{S}$ and $C^{B}$; (iv) the profit that can be obtained by opening an additional unit compared to remaining a stand-alone bank. Introducing supranational supervision alters this trade-off by affecting (ii). From Corollary 2, we immediately deduce:

Proposition 4. (i) If $c_{f}>c^{*}$, there always exists parameter values such that supranational supervision leads to a switch from a subsidiary-MNB to a branch-MNB, or to a switch from a subsidiaryMNB to a stand-alone bank. No other change of organizational structure is possible.

(ii) If $c_{f}<c^{*}$, there always exists parameter values such that supranational supervision leads to a switch from a branch-MNB to a subsidiary-MNB, or to a switch from a stand-alone bank to a subsidiary-MNB. No other change of organizational structure is possible.

Recall that supranational supervision does not affect branch-MNBs and stand-alone banks, but only subsidiary-MNBs. Using Corollary 2, the different ways supranational supervision can affect the optimal structure of the MNB are intuitive.

When $c_{f}>c^{*}$, the supranational supervisor internalizes the monitoring effect and monitors the subsidiary more, thus reducing the subsidiary's profit. The MNB can react by opening a branch instead of a subsidiary. If the cost $C^{B}$ of operating a branch is so large that a stand-alone bank is more profitable than a branch, then the MNB shuts down its foreign activities altogether.

When instead $c_{f} \leq c^{*}$, the supranational supervisor internalizes the intervention effect and monitors the subsidiary less, thus increasing the subsidiary's profit. The MNB can react by opening a subsidiary instead of a branch. If operating a branch is costly, the bank may not be able to open a foreign unit at all under national supervision, but may decide to expand abroad with a foreign subsidiary after supranational supervision is introduced.

Supranational supervision thus has opposite consequences on the MNB's structure depending 
on whether $c_{f}$ is larger than $c^{*}$. Fortunately, which case obtains depends on a simple criterion: if monitoring the foreign unit is costly then supranational supervision fosters a switch to the branch structure or domestic retreat. If monitoring the foreign unit is cheap then supranational supervision favors the subsidiary structure or foreign expansion.

\subsection{Supranational supervision and welfare}

Finally, we analyze the impact of supranational supervision on total welfare. Welfare can be expressed as the sum of the MNB's profit and the total public costs, weighted by $1+\lambda$, which comprise the monitoring costs and the expected losses of the two deposit insurance funds. Note that depositors always break even and do not need to be considered in welfare computations. First, we consider the case in which supranational supervision leaves the MNB's organizational structure unchanged:

Corollary 3. If the parameters are such that the MNB adopts a subsidiary structure both under national and supranational supervision, and $\left(d_{h}^{*}, d_{f}^{*}\right) \neq\left(d_{h}^{* *}, d_{f}^{* *}\right)$, then (i) if $c_{f} \geq c^{*}$ the total public costs decrease, the MNB's profit decreases, and there exists $\bar{\lambda}_{1}>0$ such that total welfare increases if and only if $\lambda \geq \bar{\lambda}_{1}$; (ii) if $c_{f}<c^{*}$ the total public costs decrease, the MNB's profit increases, and total welfare increases.

When the MNB does not find it optimal to adjust its organizational structure, centralizing supervision thus always decreases the total public costs. Interestingly, when $c_{f}<c^{*}$ the MNB also benefits from supranational supervision: due to the intervention effect the foreign supervisor was intervening too much, at the expense of both the MNB and the home supervisor.

When instead the MNB can adjust its organizational structure, supranational supervision can actually increase total public costs:

Corollary 4. If the parameters are such that the MNB has a foreign unit both under national and supranational supervision but with different organizational structures, and $C^{B} \leq C^{S}$, then (i) if $c_{f} \geq c^{*}$ the MNB switches from a subsidiary to a branch, the total public costs decrease, the MNB's profit decreases, and total welfare increases; (ii) if $c_{f}<c^{*}$ the $M N B$ switches from a branch to a subsidiary, the total public costs increase, the MNB's profit increases, and total welfare decreases.

We focus here on the case of higher operating costs for the subsidiary, i.e., $C^{B} \leq C^{S}$, which seems empirically more relevant (see p. 10). ${ }^{20}$ In this case, a branch is better for total welfare than a

\footnotetext{
${ }^{20}$ The results on profits and total welfare can be reversed if $C^{B}$ is sufficiently larger than $C^{S}$ instead, but the results on total public costs are unaffected.
} 
subsidiary: because both units support each other, branch-MNBs require less supervision (Corollary 1) and allow to save on monitoring costs, and the operating costs are also lower. ${ }^{21}$ When $c_{f} \geq c^{*}$, the supranational supervisor monitors the subsidiary more, which incentivizes the MNB to use a branch instead, which improves welfare. Conversely, when $c_{f}<c^{*}$, the supranational supervisor monitors the subsidiary less, and the MNB can switch from a branch to a subsidiary, which harms welfare. In such a case, national supervision is a better arrangement than supranational supervision. It is a way for supervisors to commit to being tough on a subsidiary and make the MNB prefer the branch structure. Similarly, national supervision can be necessary to have the MNB invest abroad:

Corollary 5. If the parameters are such that supranational supervision affects the MNB's decision to open a foreign unit, there exist $\bar{\lambda}_{2}>0$ and $\bar{\lambda}_{3}>0$ such that: (i) if $c_{f} \geq c^{*}$ then the MNB shuts down its subsidiary and becomes a stand-alone bank, the total public costs decrease, the MNB's profit decreases, and total welfare decreases if $\lambda \leq \bar{\lambda}_{2}$; (ii) if $c_{f}<c^{*}$ then the MNB opens a subsidiary abroad, the total public costs increase, the MNB's profit increases, and total welfare increases if $\lambda \leq \bar{\lambda}_{3}$

Unless the cost of public funds $\lambda$ is too large, opening a foreign unit is socially valuable. Then, an unintended effect of increasing the monitoring of the subsidiary can be to make the MNB withdraw from the foreign country, which harms total welfare. In this case again national supervision is more desirable than supranational supervision. In contrast to the previous Corollary, national supervision can be desirable here as a commitment to being lenient with the subsidiary, so as not to discourage the MNB from opening a unit abroad.

Finally, notice that supranational supervision also leads to a redistributive effect among the two national deposit insurance funds:

Corollary 6. If the parameters are such that supranational supervision affects the MNB's structure, (i) if $c_{f} \geq c^{*}$ the losses to the home deposit insurance fund increase, while losses to the foreign deposit insurance fund become null; (ii) if $c_{f}<c^{*}$ the losses to the home deposit insurance fund decrease, while losses to the foreign deposit insurance fund become strictly positive.

The redistributive effect is intuitive: when the MNB's organizational structure changes from subsidiary to branch or from subsidiary to stand-alone, the foreign deposit insurance fund is no

\footnotetext{
${ }^{21}$ Note that when $C^{B}=C^{S}$, for given supervisory decisions the branch structure leads to a higher welfare than the subsidiary structure. Indeed, as the failure of either unit triggers the default of the bank and implies that all the bank's assets are used to reimburse depositors, this structure minimizes the losses of the deposit insurance fund. The branch structure thus provides a form of "coinsurance", as in Banal-Estanol, Ottaviani, and Winton (2013), but for a different reason.
} 
longer liable, and the home deposit insurance fund either becomes liable for an extra unit (branch case), or loses access to the foreign unit's residual assets (stand-alone case). The opposite obtains when the MNB's organizational structure changes from stand-alone or branch to subsidiary.

\section{Empirical implications}

We briefly review the main testable implications of the model in this Section. We first discuss how the variables of our model can be mapped to the data, and then give three implications relating the MNB's change in organizational structure with the level of supervisory monitoring and with the quality of supervision.

\subsection{Mapping the model to the data}

The main endogenous variable of the model is the MNB's organizational structure, which is empirically observable. There is significant heterogeneity in the organizational structures of MNBs in the data. ${ }^{22}$ The empirical literature illustrates that the decision on the type of organizational structure depends on several factors, including differences in regulation and supervision, which we focus on (see for example Cerutti, Dell'Ariccia, and Martinez Peria (2007) and Fiechter et al. (2011)).

The other important endogenous variable in the model is the intensity of supervisory monitoring in each unit, $\left(d_{h}, d_{f}\right)$. This can be estimated directly with data on hours spent by bank supervisors (as in Eisenbach, Lucca, and Townsend (2016)), or indirectly by using market and accounting variables (Carbo-Valverde, Kane, and Rodriguez-Fernandez (2012)), or by measuring the bank's asset risk. For instance, Fiordelisi, Ricci, and Stentella Lopes (2017) show that the SSM led European banks to rebalance their portfolios towards safer assets on average, which is in line with increased monitoring by the supranational supervisor when the monitoring effect dominates the intervention effect. We also give predictions on the MNB's profitability, which is easily observable.

Our model relates these endogenous variables to the centralization of supervision, of which the creation of the SSM is the prime empirical example, and to supervisory monitoring costs. The monitoring costs $c_{h}$ and $c_{f}$ can be linked to the efficiency of supervision at the country level, as proxied for instance by the "Official Supervisory Action Variables" and "Official Supervisory Structural Variables" in Barth, Caprio, and Levine (2013).

\footnotetext{
${ }^{22}$ See the ECB data on structural financial indicators mentioned in Footnote 3.
} 


\subsection{Correlations between organizational structure, monitoring, and profit}

A first empirical exercise suggested by our model is to look at foreign units of MNBs in the Euro area after the introduction of the SSM and test how their profitability, monitoring and organizational structure are affected. A simple implication of Proposition 3 is the following:

Implication 1. Consider the foreign subsidiary of a MNB. If its organizational structure does not change following the introduction of supranational supervision, supervisory monitoring of the subsidiary increases (resp. decreases) and profitability decreases (resp. increases) if the monitoring costs $c_{f}$ are high (resp. low). A foreign branch is unaffected.

This implication applies in particular in the short-run, before MNBs are able to adjust their organizational structure to the new supervisory environment. In the long-run, accounting for the possibility of a change in the organizational structure:

Implication 2. When a MNB changes its organizational structure following the introduction of supranational supervision, monitoring (weakly) decreases in both the home and the foreign units. If a subsidiary is transformed into a branch the total profit of the MNB decreases, if a branch is converted into a subsidiary the total profit increases.

Simple inspection of Figures 2 and 3 shows this implication. When supranational supervision would intensify monitoring of the subsidiary (i.e. $c_{f}>c^{*}$ ), the decisions of the national supervisors are $(M, O)$ and the bank, by switching to a branch-MNB, induces decisions $(O, O)$. When instead supranational supervision reduces monitoring of the subsidiary (i.e. $c_{f} \leq c^{*}$ ), the bank faces decisions $(O, O)$ both with the original branch structure and with the new subsidiary structure.

These predictions are quite specific to our model, as they depend on the endogenous adjustment of the MNB's organizational structure to the level of supervision. In particular, two points are quite counter-intuitive: (i) a change in the organizational structure of the foreign unit also has an impact on monitoring in the home unit; (ii) when supranational supervision leads to more monitoring of a subsidiary, the endogenous change in organizational structure ultimately leads to less monitoring of the foreign unit.

\subsection{Explaining changes in the organizational structure}

Our model gives predictions on which foreign units will be affected by the introduction of supranational supervision, and on whether subsidiaries will be transformed into branches or the opposite, 
or whether a foreign unit will be closed or opened. To test such predictions, one can conduct a difference-in-differences analysis as in Fiordelisi, Ricci, and Stentella Lopes (2017), who estimate the average impact of the SSM on the affected banking groups, also allowing for country-specific effects. Our model suggests to extend such an analysis in two directions: (i) to test our model, the analysis must be conducted at the banking unit level, not at the banking group level; (ii) while the average impact of the SSM is potentially ambiguous, the cross-sectional heterogeneity of this impact can be explained by both home and host country characteristics, so that one should interact the SSM "treatment" with such characteristics, or consider home/host country pairs, as in, e.g., Karolyi and Taboada (2015).

Our main predictions regarding the change in organizational structure derive from Proposition 3, and are illustrated by the right panel of Fig. 3:

Implication 3. If $c_{f}$ is high and $c_{h}$ takes an intermediate value, a foreign subsidiary may be turned into a branch, or shut down.

If $c_{f}$ is low and $c_{h}$ is high, a foreign branch may be turned into a subsidiary, or a new foreign subsidiary opened.

A way to test these predictions would be to compare banking units in the same host country with parent banks in different home countries (impact of $c_{h}$ ), and units in different host countries with parent banks in the same home country, or even with the same parent bank (impact of $c_{f}$ ).

This implication can be related to the literature on cross-border acquisitions (opening a subsidiary) and divestitures (closing a foreign unit). We expect supranational supervision to lead to more acquisitions of banks in countries with low monitoring costs, and fewer in other countries. The counter-intuitive case in which supranational supervision leads to divestiture and a decrease in cross-border activities is particularly interesting. When this happens, it means that the subsidiary was profitable only because it was weakly supervised, corresponding to a case in which multinational banks invest via subsidiaries in countries with weaker supervision to take more risk (e.g., Ongena, Popov, and Udell (2013)). Indeed, there is evidence that banks from well-regulated countries tend to acquire banks in more weakly-regulated areas (see Karolyi and Taboada (2015)), and that acquisitions are partly driven by MNB's wanting to extract more safety net subsidies (Carbo-Valverde, Kane, and Rodriguez-Fernandez (2012)). 


\section{Extensions}

In this Section we develop several extensions of the baseline model: ring-fencing of the subsidiary's assets, support of the subsidiary by the parent bank, the possibility that the deposit insurance fund is unable to repay the depositors, failure-related externalities, and "organizational structuresensitive" deposit insurance premia.

\subsection{Alternative liability structures}

Our model is versatile enough to consider variations of the subsidiary's liability structure on our main results. Here, we consider ring-fencing the subsidiary's assets, and the possibility that the parent bank rescues a failing subsidiary.

Ring-fencing. Assume that when the home unit fails, and the foreign unit is successful, the home supervisor can only use a fraction $\beta \leq 1$ of the subsidiary's residual assets. The analysis of the baseline model remains valid, except that the quantities $\rho$ and $\rho_{i}$ have to be multiplied by $\beta$. This reduction of the value of the foreign unit's residual assets increases the incentives to monitor the home unit. This reinforces the result of Corollary 1: under ring-fencing, a subsidiary-MNB is even more likely to face more monitoring than a branch. Thus, the main trade-off between the two structures remains qualitatively similar for the MNB.

Interestingly, ring-fencing lowers welfare in our model by reducing the fraction of foreign residual assets that the home supervisor can use to reimburse depositors of a failed home unit. This implies that the home supervisor needs to raise more of the costly public resources in order to make up for the losses of the home unit. ${ }^{23}$

To understand how ring-fencing affects our results on supranational supervision, note that the intervention effect $\eta_{I}$ is still given by (12), but with the residual assets multiplied by $\beta$. A simple inspection of the expressions shows that as ring-fencing increases, i.e., $\beta$ decreases, the magnitude of the intervention effect decreases. Ring-fencing decreases the residual assets that the home supervisor can access and thereby lowers the impact of foreign intervention on the home supervisor's cost. Similarly, the expression for the monitoring effect $\eta_{M}$ is still given by (11), but with the residual assets multiplied by $\beta$. It is easy to check that ring-fencing diminishes the monitoring effect when monitoring the home unit is optimal under national supervision, while it accentuates it when monitoring the home unit is not optimal under national supervision.

\footnotetext{
${ }^{23}$ See Cerutti et al. (2010) for an empirical estimate of the costs, in terms of capital, of different ring-fencing frameworks for European banks regarding their subsidiaries in Central, Eastern, and Southern Europe.
} 
Ring-fencing can thus affect the impact of supranational supervision in diverse ways. If the MNB's home unit is not monitored under national supervision, then more ring-fencing of the subsidiary makes it more likely that supranational supervision leads to more monitoring of the subsidiary and possibly a switch from subsidiary to branch. If the MNB's home unit is monitored, then more ring-fencing has an ambiguous effect on the supervision externality and may make it either more or less likely that supranational supervision leads to more monitoring.

Rescue of failed subsidiaries. The MNB may choose to use some of the home unit's assets to rescue a failing subsidiary, for instance due to reputational issues. ${ }^{24}$ In our model, the home unit never has sufficient funds to prevent the foreign unit from failing (assumption (H2)). However, the bank can use the residual assets of the home unit to partially reimburse depositors in the foreign country. Even in this case, there is still less pooling of resources with a subsidiary organization than with a branch organization, under which the home unit's assets are used to reimburse depositors in both countries, equally. Thus, the difference in liability structures between branches and subsidiaries is still relevant.

Interestingly, this variant of the model also introduces two new externalities: because now the foreign supervisor can use the home unit's residual assets, the home supervisor exerts both an intervention effect and a monitoring effect on the foreign supervisor. While a full analysis of the impact of supranational supervision in this case is beyond the scope of this paper, the presence of additional externalities suggests that the outcomes of national and supranational supervision may differ even more than in the baseline version of the model.

\subsection{Weak deposit insurance}

In countries with a high level of government debt or a large banking sector relative to GDP, the government's ability to honor formal commitments to depositors raises considerable doubts (DemirgucKunt, Kane, and Laeven (2014)). In this subsection, we consider the impact of weak deposit insurance on our results.

Intuitively, weak deposit insurance affects the rate at which depositors are willing to lend to the bank: the less credible the deposit insurance in charge is, the higher is the rate demanded by

\footnotetext{
${ }^{24}$ It is not to be expected that MNBs are always going to rescue their subsidiaries. For instance, during the Argentine crisis of 2000-2001 Credit Agricole reduced its losses by permitting a government takeover of its subsidiaries. Similarly, Bayerische Landesbank gave up its Croatian subsidiary following large-scale deposit withdrawals in 2002. During the recent financial crisis policymakers were concerned that European MNBs would withdraw support and funding from their subsidiaries in emerging Europe, and launched the Vienna Initiative to avoid such an outcome, see for example Haas et al. (2015).
} 
depositors. Higher deposit rates in turn imply lower residual assets that can be transferred from a solvent unit to reduce losses in a failing one. Hence, as we argue more formally below, the effect of a weak deposit insurance on our results is qualitatively similar to the one of ring-fencing.

To accommodate for the effect of weak deposit insurance, assume that the deposit insurance fund in country $i$ fully reimburses depositors only with probability $\alpha_{i} \leq 1$. Since depositors can now make a loss on their deposit, they demand a higher rate than the risk-free one. For example, in the case of the subsidiary, between $t=1$ and $t=2$ the bank offers interest rates $P_{h} \geq 1$ and $P_{f} \geq 1$ to depositors in the two countries, who then choose whether to deposit or not. Depositors in country $i$ are repaid $P_{i}$ when the unit is successful, or the deposit insurance fund can repay, but only receive the residual assets available on the balance sheet when the deposit insurance fund is unable to pay. The rates $P_{i}$ are determined endogenously and make depositors indifferent between depositing their money at the bank or not. Importantly, not fully credible deposit insurance makes the rate dependent on the supervisors' decisions. Depositors in the foreign subsidiary for instance ask for a rate $P_{f}\left(d_{f}\right)$ defined by:

$$
\begin{aligned}
\theta P_{f}(M)+(1-\theta) P_{f}(M) & =1 \\
\theta P_{f}(O)+(1-\theta)\left[p P_{f}(O)+(1-p) \alpha_{f}\right] & =1 .
\end{aligned}
$$

When the supervisor monitors, the corresponding unit is always solvent: the deposit rate is equal to 1 and does not depend on the credibility of the deposit insurance funds. When the supervisor does not monitor, the deposit rates depend negatively on the strength of the local deposit insurance fund. Moreover, in the case of the subsidiary, the strength of the foreign deposit insurance fund also matters for the rate at which the home unit can raise money. Weaker foreign deposit insurance lowers the residual assets available for home depositors from the subsidiary when the home unit fails. Indeed, $R-P_{f}$ increases in $\alpha_{f}$ via a reduction in the rate $P_{f}$. With a branch-MNB, a deterioration of $\alpha_{h}$ increases both $P_{h}$ and $P_{f}$ as long as the supervisor does not opt for monitoring both units. Otherwise, rates will be independent of the credibility of the (home) deposit insurance. ${ }^{25}$

\footnotetext{
${ }^{25}$ In line with this reasoning, Bonfim and Santos (2017) show that some foreign banks operating in Portugal converted their subsidiaries into branches in 2010 and 2011 when the Portuguese deposit insurance fund became less credible. Conversely, in 2015 all foreign units of Greek banks were subsidiaries, except for Alpha Bank which had branches in Romania and Bulgaria. Facing the deterioration of the Greek national deposit insurance, Alpha Bank faced the largest withdrawal of deposits of all foreign units of Greek banks. Its branches were shortly after acquired (July 2015) by other Greek banks and reorganized into subsidiaries, backed-up by the more solid Romanian and Bulgarian national deposit insurance (see "Greek Eurobank Takes Over Alpha Bank's Branch Network in Bulgaria," July 18, 2015, at www.novinite.com).
} 
The consequences of weak deposit insurance are similar to those of ring-fencing since it also reduces residual assets, as seen above. The reduction of residual assets due to weak deposit insurance decreases the magnitude of the intervention effect but it has the same ambiguous consequences on the monitoring effect: weaker deposit insurance (i.e. lower $\alpha_{f}$ ) diminishes the monitoring effect when monitoring the home unit is optimal under national supervision, while it accentuates it when not monitoring the home unit is optimal. Hence, if the MNB's home unit is not monitored under national supervision, then weaker deposit insurance makes it more likely that supranational supervision leads to more monitoring of the subsidiary and the bank would prefer to switch from subsidiary to branch. If the MNB's home unit is monitored, then weaker deposit insurance may make it either more or less likely that supranational supervision leads to more monitoring.

\subsection{Failure externalities}

A bank's failure may spur additional costs on the economy. Let $e_{i} \geq 0$ be the externality-cost of the failure of unit $i$ that adds up to the other costs considered so far in that country. ${ }^{26}$ With a subsidiary structure the national supervisor in country $i$ would account for $e_{i}$ in the costs of failure, thus making monitoring unit $i$ more likely than when $e_{i}=0$, as was the case in the previous sections. With a branch structure instead, the home supervisor disregards $e_{f}$ and would then monitor the foreign unit relatively less than the foreign supervisor of a subsidiary-MNB, thus reinforcing Corollary 1.

A well-conceived supranational supervisory framework should instead internalize these externalities. First, the externality $e_{f}>0$ makes the supranational supervisor monitor the foreign unit of a branch-MNB more than the national supervisor. Second, with a subsidiary structure the externality plays no role because it would be accounted for by the supervisors in any case. Hence, we can conclude that when failure externalities are present, supranational supervision makes a change from subsidiaries to branches less likely, and a change from branches to subsidiaries more likely.

\subsection{Organizational structure-sensitive insurance premia}

As is well known in the theoretical literature, risk-based insurance premia can go a long way towards alleviating moral hazard in banking (see, e.g., Rochet (1992)). In this model, one needs to go even further to align incentives with the social optimum: the premia should depend on the organizational structure of the bank. Indeed, for a given premium, a subsidiary-MNB enjoys an implicit subsidy, when compared to a branch or a stand-alone: with a certain probability, its foreign creditors are

\footnotetext{
${ }^{26}$ Externalities may be more pervasive. For example, the failure of unit $i$ may also induce a cost $e_{i j}$ on country $j$.
} 
repaid by the foreign deposit insurance fund, even though the home unit redistributes profits to shareholders.

To see how a premium based on the organizational structure can align the incentives of the bank with the social optimum, assume that the MNB needs to pay fees $F_{h}(\sigma)$ and $F_{f}(\sigma)$ up-front to the deposit insurers of countries $h$ and $f$, respectively, where $\sigma \in\{S, B, A\}$ stands for the MNB's organizational structure. A fairly priced deposit insurance would imply that the bank pays exactly the expected costs to each deposit insurer. This is equivalent to having:

$$
\begin{array}{cl}
F_{h}(S)=-(1+\lambda) W_{h}\left(d_{h}^{*}, d_{f}^{*}\right), & F_{f}(S)=-(1+\lambda) W_{f}\left(d_{f}^{*}\right) \\
F_{h}(B)=-(1+\lambda) W_{b}\left(d_{h}^{b}, d_{f}^{b}\right), & F_{f}(B)=0 \\
F_{h}(A)=-(1+\lambda) W_{h}\left(d_{h}^{*}\right), & F_{f}(A)=0 .
\end{array}
$$

The same formulas hold under supranational supervision, replacing $\left(d_{h}^{*}, d_{f}^{*}\right)$ with $\left(d_{h}^{* *}, d_{f}^{* *}\right)$. To see why with such premia the MNB's organizational structure is socially optimal, observe that the MNB will for instance choose $S$ over $B$ if and only if $\Pi\left(S, d_{h}^{*}, d_{f}^{*}\right)-F_{h}(S)-F_{f}(S)-C^{S} \geq \Pi\left(B, d_{h}^{b}, d_{f}^{b}\right)-$ $F_{h}(B)-C^{B}$, which is simply equivalent to $\Pi\left(S, d_{h}^{*}, d_{f}^{*}\right)-C^{S}+(1+\lambda) W_{h}\left(S, d_{h}^{*}, d_{f}^{*}\right)+(1+\lambda) W_{f}\left(d_{f}^{*}\right) \geq$ $\Pi\left(B, d_{h}^{b}, d_{f}^{b}\right)-C^{B}+(1+\lambda) W_{b}\left(d_{h}^{b}, d_{f}^{b}\right)$ : the MNB is in effect maximizing welfare.

While theoretically natural, this solution may be difficult to implement. First, it requires to have a good understanding of the often complicated structure of the entire MNB, as this structure has a first-order impact on the distribution of losses in case the MNB defaults. Second, the insurance premium should correctly anticipate and price in the optimal supervisory decisions. To our knowledge, none of these elements are priced in existing deposit insurance schemes.

Finally, note that this approach does not make supranational supervision redundant, as it still leads to more monitoring when $c_{f} \geq c^{*}$ and less otherwise. A conclusion from our model is that making insurance premia depend on the MNB's structure, while complicated, is necessary to control the MNB's incentives to change its organizational structure so as to extract more implicit subsidies from deposit insurance funds. In particular, our results on welfare (Section 3.3) show that one cannot simply complement supranational supervision with uniform restrictions on the banks' foreign organization. For example, the opening of a new foreign subsidiary can be beneficial and the conversion of an existing foreign unit into a subsidiary can be detrimental. 


\section{Conclusion}

We propose a framework to understand the interaction between the architecture of bank supervision in an international environment and the organizational structure of multinational banks. This interaction is important to evaluate the impact of recent supervisory reforms aiming at increasing coordination in supervision, as with the recent European Banking Union and Single Supervisory Mechanism.

We argue that centralization of bank supervision at a supranational level provides incentives for MNBs to adjust their foreign activities to the new supervisory arrangement. Accounting for these incentives has important implications for banks' profit, supervision costs, deposit insurance costs, and total welfare. For example, we show that when supranational supervision leads to less monitoring in foreign subsidiaries, MNBs adjust by converting branches into subsidiaries. Once this effect is taken into account, supranational supervision ends up increasing the cost of insuring deposits and reducing welfare.

More broadly, our study shows that reforms of supervision and regulation should not take the industry structure as given. The strategic reaction of banks can be substantial and, in some cases, unwind the intended consequences of reforms. We think this is a general message that goes behind the case of supranational supervision. Other recent or debated reforms, such as forcing subsidiaries to operate under the common umbrella of a holding company, ${ }^{27}$ giving more supervisory powers to host countries ${ }^{28}$ introducing a common European deposit insurance, or letting national supervisors ring-fence local activities of foreign banks, all affect branches and subsidiaries differently and may also lead MNBs to adjust their structure. While these new policies are worthy of deeper investigation in future work, we think our analysis and the externalities we have identified are helpful to think about potential unintended consequences of these reforms.

\footnotetext{
${ }^{27}$ In the U.S., since 2014 the Federal Reserve requires large foreign banking organizations with significant presence in the U.S. to operate their U.S. subsidiaries under an "intermediate holding company" supervised by the Federal Reserve. Similarly, in 2017 the European Commission announced plans to require non-E.U. subsidiaries to operate under an "intermediate parent undertaking".

${ }^{28}$ The European Banking Authority published guidelines in 2017 giving more powers to host supervisors of "significant-plus" branches, with a systemic importance for the host country.
} 


\section{A Appendix}

\section{A.1 Proof of Proposition 1}

As shown in the text for the case of a standalone bank, the foreign supervisor chooses $d_{f}^{*}=O$ if $c_{f}>c^{*}$, and $d_{f}^{*}=M$ otherwise. In particular, note that it is useless for the foreign supervisor to monitor and not intervene when the assets are bad, so that we don't need to consider any other decision than $M$ and $O$. We consider the home supervisor's decision in each case.

- Case $c_{f}>c^{*}$ : no monitoring in the foreign unit. It is again pointless for the home supervisor to monitor the home unit and not intervene when the assets are bad. Since the foreign unit is not monitored, the home supervisor cannot condition his monitoring decision on the quality of assets in the foreign unit. Hence, we only need to compare the decisions $d_{h}=O$ and $d_{h}=M$. If the home unit is not monitored, the home deposit insurance fund will take losses with probability $(1-\theta)(1-p)$. Conditionally on this happening, with probability $\theta+(1-\theta) p$ the foreign unit will be profitable and give some residual assets worth $R-1$, otherwise the loss of the home deposit insurance fund will just be 1 . So we have:

$$
W_{h}(O, O)=(1-\theta)(1-p)[-1+\rho(O)]
$$

If the home unit is monitored, the probability of default is reduced to 0 :

$$
W_{h}(M, O)=-c_{h}
$$

As a result, the home unit in this case will be monitored if and only if $c_{h} \leq(1-\theta)(1-p)[1-\rho(O)]=$ $c^{*}[1-\rho(O)]$.

- Case $c_{f} \leq c^{*}$ : monitoring in the foreign unit. In addition to the decisions $O$ and $M$, the home supervisor can also take a monitoring decision conditionally on foreign assets being bad (decision $C$ ), or conditionally on foreign assets being good (a decision we denote $C^{\prime}$ ). Similarly to the case $c_{f}>c^{*}$, we have:

$$
\begin{aligned}
W_{h}(O, M) & =(1-\theta)(1-p)[-1+\rho(M)] \\
W_{h}(M, M) & =-c_{h} .
\end{aligned}
$$

Now consider decision $C$. With probability $1-\theta$ the foreign unit has bad assets. The home supervisor 
monitors and intervenes when the unit's assets are bad, reducing the losses to the deposit insurance funds to zero. With probability $\theta$, the foreign unit has good assets, the home unit is not monitored and the deposit insurance fund suffers losses of $1-\rho_{g}(M)$ with probability $(1-\theta)(1-p)$. This gives:

$$
W_{h}(C, M)=\theta \times(1-\theta)(1-p)\left[-1+\rho_{g}(M)\right]+(1-\theta) \times\left(-c_{h}\right) .
$$

Decision $C^{\prime}$ gives a symmetric payoff:

$$
W_{h}\left(C^{\prime}, M\right)=\theta \times\left(-c_{h}\right)+(1-\theta) \times(1-\theta)(1-p)\left[-1+\rho_{b}(M)\right] .
$$

Comparing the different payoffs, we obtain that $W_{h}\left(C^{\prime}, M\right) \geq W_{h}(M, M)$ if and only if $c_{h} \geq$ $c^{*}\left(1-\rho_{b}(M)\right)$ and $W_{h}\left(C^{\prime}, M\right) \geq W_{h}(O, M)$ if and only if $c_{h} \leq c^{*}\left(1-\rho_{g}(M)\right)$. Since $\rho_{g}(M) \geq \rho_{b}(M)$,

the two previous conditions are incompatible and decision $C^{\prime}$ can never be optimal, and we are left with a comparison of $O, M$, and $C$. We have:

$$
\begin{gathered}
W_{h}(M, M) \geq W_{h}(C, M) \quad \Leftrightarrow \quad c_{h} \leq c^{*}\left(1-\rho_{g}(M)\right) \\
W_{h}(M, M) \geq W_{h}(O, M) \quad \Leftrightarrow \quad c_{h} \leq c^{*}(1-\rho(M)) \\
W_{h}(C, M) \geq W_{h}(O, M) \quad \Leftrightarrow \quad c_{h} \leq c^{*}\left(1-\rho_{b}(M)\right)
\end{gathered}
$$

Noting that $\rho_{g}(M) \geq \rho(M) \geq \rho_{b}(M)$, the Proposition follows.

\section{A.2 Proof of Proposition 2}

As the branch has a symmetric structure and $c_{h} \leq c_{f}$, we know that that the foreign unit cannot be more monitored than the home unit. Thus $\left(d_{h}^{b}, d_{f}^{b}\right) \in\{(O, O),(M, O),(M, C),(M, M)\}$. There are two additional strategies to consider, but they are never optimal and can thus be ignored, as we shall show at the end of this proof. Given the liability structure and the fact that $R \leq 2$, the deposit insurance fund suffers losses if and only if at least one unit fails. We first compute the supervisor's payoff for each decision pair, and then compare the different payoffs.

Under decision $(O, O)$, each unit fails with probability $(1-\theta)(1-p)$. If one unit is successful, the amount $R$ can be used to partially offset the losses. This gives:

$$
\begin{aligned}
W_{b}(O, O) & =[(1-\theta)(1-p)]^{2}(-2)+2(1-\theta)(1-p)[\theta+(1-\theta) p](R-2) \\
& =2(1-\theta)(1-p)(\rho(O)-1)
\end{aligned}
$$


After some simplifications, we thus obtain that $W_{b}(O, O)$ can be simply rewritten as a function of the residual assets under decision $O, \rho(O)$.

Under decision $(M, O)$, with probability $(1-\theta)(1-p)$ the foreign unit fails. As $R<2$, the deposit insurance fund needs to reimburse 2 to the depositors, and can use on average $\theta R+(1-\theta) r$ of assets from the home unit to partially offset the losses. With complementary probability $\theta+(1-\theta) p$ the foreign unit is successful and the deposit insurance funds incur no losses as $r+R>2$. We obtain:

$$
\begin{aligned}
W_{b}(M, O) & =(1-\theta)(1-p)[\theta R+(1-\theta) r-2]-c_{h} \\
& =(1-\theta)(1-p)[\rho(M)-1]-c_{h}
\end{aligned}
$$

Under decision $(M, C)$, the foreign unit is monitored only if the home unit has bad assets. With probability $\theta$, the home unit has good assets, in which case the deposit insurance fund loses money only if the foreign unit defaults, which happens with probability $(1-\theta)(1-p)$. With probability $(1-\theta)$ the home unit has bad assets, the foreign unit is monitored and bad units are restructured, reducing the losses to the deposit insurance to zero. This gives us:

$$
W_{b}(M, C)=\theta(1-\theta)(1-p)(R-2)-c_{h}-(1-\theta) c_{f}
$$

Finally, consider decision $(M, M)$. The home supervisor incurs the monitoring costs for both units. However, monitoring enables the supervisor to restructure failing units and reduce the losses to the deposit insurance funds to zero. We obtain:

$$
W_{b}(M, M)=-c_{h}-c_{f}
$$

We can now compare the different payoffs. Using $r=p R$, we have $\rho(O)=\rho(M)+(1-\theta)(1-p)$ 
and $\rho_{b}(O)=\rho_{b}(M)+1-p$. Using these equalities, we can derive the following equivalences:

$$
\begin{array}{lll}
W_{b}(M, M) \geq W_{b}(M, C) \quad \Leftrightarrow \quad & c_{f} \leq c^{*}\left[1-\rho_{g}(M)\right] \\
W_{b}(M, M) \geq W_{b}(M, O) \quad \Leftrightarrow \quad & c_{f} \leq c^{*}[1-\rho(M)] \\
W_{b}(M, M) \geq W_{b}(O, O) \quad \Leftrightarrow \quad & c_{f}+c_{h} \leq 2 c^{*}[1-\rho(O)] \\
W_{b}(M, C) \geq W_{b}(M, O) \quad \Leftrightarrow \quad & c_{f} \leq c^{*}\left[1-\rho_{b}(M)\right] \\
W_{b}(M, C) \geq W_{b}(O, O) \quad \Leftrightarrow \quad & c_{h}+(1-\theta) c_{f} \leq c^{*}[1-\rho(O)] \\
& & \left.+(1-\theta) c^{*}\left[1-\rho_{b}(O)\right)\right] \\
W_{b}(M, O) \geq W_{b}(O, O) & \Leftrightarrow & c_{h} \leq c^{*}[1-(1-\theta)(1-p)-\rho(O)] .
\end{array}
$$

Observe that in order for $(M, C)$ to be optimal we need $c^{*}\left[1-\rho_{g}(M)\right] \leq c^{*}\left[1-\rho_{b}(M)\right]$ (equations (A.12) and (A.15)), which is equivalent to $(2-r) \geq 2-R$, which is true as $r<R$. Thus, (A.13) is implied by (A.12), so that $(M, M)$ obtains when (A.12) and (A.14) are satisfied. $(M, C)$ obtains when (A.15) and (A.16) are satisfied and (A.12) is not. For $(M, O)$, if $W_{b}(M, O) \geq W_{b}(M, C)$ then $W_{b}(M, O) \geq W_{b}(M, M)$, so that $(M, O)$ obtains if and only if (A.17) is satisfied and not (A.15)). $(O, O)$ obtains otherwise.

To conclude the proof, we need to exclude two additional possible decisions, which we do in the Online Appendix B.1.

\section{A.3 Proof of Corollary 1}

We first consider the case $c_{h} \leq c_{f}$.

Point (i): If $d_{f}^{*}=O$ then according to Proposition $1 c_{f} \geq c^{*}$. According to inequalities (A.12) and (A.15) in the proof of Proposition 2, this implies that $\left(d_{h}^{b}, d_{f}^{b}\right)$ can be neither $(M, M)$ nor $(M, C)$, so that necessarily $d_{f}^{b}=O$.

Point (ii): Using again Propositions 1 and 2, we need to show that $c_{f}>c^{*}$ and $c_{h}>c^{*}(1-\rho(O))$ imply that (A.14), (A.16), and (A.17) are violated.

This is obvious for (A.17), since $c^{*}[1-\rho(O)]>c^{*}[1-(1-\theta)(1-p)-\rho(O)]$. For (A.16) it is sufficient to show that $c^{*}[1-\rho(O)]+(1-\theta) c^{*}>[1-\rho(O)] c^{*}+(1-\theta)\left[1-\rho_{b}(O)\right] c^{*}$, which is obviously true. Finally, for (A.14) one needs to show that $c^{*}(2-\rho(O)) \geq 2 c^{*}[1-\rho(O)]$, which is true.

In the case $c_{h}>c_{f}$ we can prove a stronger result: if $d_{f}^{*}=O$ then $\left(d_{h}^{b}, d_{f}^{b}\right)=(O, O)$. Since $d_{f}^{*}=O$ we have $c_{f} \geq c^{*}$, so that $c_{h}>c^{*}$. This, together with the conditions equivalent to (A.12)- 
(A.16) for the case $c_{h}>c_{f}$ (thus inverting the indexes in those expressions), imply that the only possible decisions with branch-MNB are $(O, O),(O, M)$. However, $(O, M)$ is impossible because the equivalent of condition (A.17) is incompatible with $c_{f} \geq c^{*}$.

\section{A.4 Proof of Lemma 1}

By contradiction, assume this is not the case and we have $d_{f}^{*}=d_{f}^{* *}$ with $d_{h}^{*} \neq d_{h}^{* *}$. The supranational supervisor chooses a pair of decisions. In particular, since the pair $\left(d_{h}^{* *}, d_{f}^{* *}\right)$ is optimal:

$$
W_{h}\left(d_{h}^{* *}, d_{f}^{* *}\right)+W_{f}\left(d_{f}^{* *}\right) \geq W_{h}\left(d_{h}^{*}, d_{f}^{* *}\right)+W_{f}\left(d_{f}^{* *}\right)
$$

but since $d_{h}^{*}$ is optimal for the home supervisor in the national case, it must be a best response to $d_{f}^{*}=d_{f}^{* *}$, and in particular we must have

$$
W_{h}\left(d_{h}^{*}, d_{f}^{* *}\right) \geq W_{h}\left(d_{h}^{* *}, d_{f}^{* *}\right)
$$

Both inequalities cannot hold unless $d_{h}^{*}=d_{h}^{* *}$, a contradiction.

\section{A.5 Proof of Proposition 3}

Lemma 1 allows us to focus on identifying cases in which supranational supervision leads to a different decision in the foreign unit. For the moment we focus only on strategy pairs that can be obtained under national supervision, and postpone the other cases to the end of this proof. Denoting $\left(d_{h}^{*}, d_{f}^{*}\right) \rightarrow\left(d_{h}^{* *}, d_{f}^{* *}\right)$ the case in which national supervision leads to decisions $\left(d_{h}^{*}, d_{f}^{*}\right)$ and supranational supervision to $\left(d_{h}^{* *}, d_{f}^{* *}\right)$, we have 12 possible cases: $1 .(O, O) \rightarrow(O, M) ; 2 .(O, O) \rightarrow$ $(M, M) ; 3$. $(O, O) \rightarrow(C, M) ; 4$. $(M, O) \rightarrow(O, M) ; 5$. $(M, O) \rightarrow(M, M) ; 6 . \quad(M, O) \rightarrow(C, M)$;

7. $(O, M) \rightarrow(O, O) ; 8$. $(O, M) \rightarrow(M, O) ; 9 . \quad(M, M) \rightarrow(O, O) ; 10 . \quad(M, M) \rightarrow(M, O) ; 11$. $(C, M) \rightarrow(O, O) ; 12 .(C, M) \rightarrow(M, O)$.

We can simplify further, using the two effects we have defined and the ranking of residual assets.

First, let us prove that if $d_{f}^{*}=O$ and $d_{f}^{* *}=M$ then $d_{h}^{* *}=C$, so that we can eliminate cases 1,2 , 4, and 5. By contradiction, assume this is not the case. By definition, we have $W_{f}(O) \geq W_{f}(M)$ due to the optimality of $O$ for the foreign supervisor. Since $\left(d_{h}^{* *}, d_{f}^{* *}\right)$ is optimal for the supranational supervisor, we also have $W_{h}\left(d_{h}^{* *}, M\right)+W_{f}(M) \geq W_{h}\left(d_{h}^{*}, O\right)+W_{f}(O)$. These two inequalities imply that we must have $W_{h}\left(d_{h}^{* *}, M\right) \geq W_{h}\left(d_{h}^{*}, O\right)$, which is equivalent to $\eta_{I} \geq 0$. This is never true, hence a contradiction. Intuitively, the supranational supervisor changes the decision in the foreign 
unit from $O$ to $M$ only if this implies a positive monitoring effect, as otherwise this change only implies a negative intervention effect.

Second, let us prove that we can eliminate cases 8 and 9 . For case 8 to be possible we need $W_{h}(O, M) \geq W_{h}(M, M)$ and $W_{h}(M, O) \geq W_{h}(O, O)$, which is equivalent to $c_{h} \geq c^{*}[1-\rho(M)]$ and $c_{h} \leq c^{*}[1-\rho(O)]$. These two conditions are not compatible, as $\rho(O)>\rho(M)$. Similarly, for case 9 we need $W_{h}(M, M) \geq W_{h}(C, M)$ and $W_{h}(O, O) \geq W_{h}(M, O)$, which is equivalent to $c_{h} \leq c^{*}\left(1-\rho_{g}(M)\right)$ and $c_{h} \geq c^{*}(1-\rho(O))$, which is again impossible as $\rho_{g}(M)>\rho(O)$.

We are thus left with six cases. We focus on the four cases that can be obtained in equilibrium, we show in the Online Appendix B.2 that the other two cases never obtain. The Online Appendix also shows that the decisions $d_{f} \in\left\{C, C^{\prime}, M^{\prime}\right\}$ can never be optimal for the supranational supervisor.

- Case 3: $(O, O) \rightarrow(C, M)$. We need to show under which conditions $(C, M)$ is optimal for the supranational supervisor, knowing that $\left(d_{h}^{*}, d_{f}^{*}\right)=(O, O)$. First, we know that $(M, O)$ is necessarily dominated by $(O, O)$ for the supranational supervisor, as $\left(d_{h}^{*}, d_{f}^{*}\right)=(O, O)$ implies that $W_{h}(O, O) \geq W_{h}(M, O)$. Second, from the reasoning above excluding cases $1,2,4$, and 5 , we know that the total welfare cannot be higher with $(O, M)$ and $(M, M)$ than with $(O, O)$. There are thus only two possibilities: either the supranational supervisor chooses $(C, M)$, or she chooses $(O, O)$. Thus, we just need to compare the payoff with both decision pairs, which gives:

$$
W_{h}(C, M)+W_{f}(M) \geq W_{h}(O, O)+W_{f}(O) .
$$

Note that $W_{f}(O)-W_{f}(M)=c_{f}-c^{*}$, which is positive because in order to have $\left(d_{h}^{*}, d_{f}^{*}\right)=(O, O)$ we need $c_{f} \geq c^{*}$. So it is necessary to have $W_{h}(C, M) \geq W_{h}(O, O)$, in which case we have $S E=$ $W_{h}(C, M)-W_{h}(O, O)$. To conclude, this case obtains if and only if $c_{h} \geq c^{*}(1-\rho(O)), c_{f} \geq c^{*}$, and $c_{f} \leq S E+c^{*}$. This defines a non-empty set of parameters, as shown on Fig. 3.

- Case 6: $(M, O) \rightarrow(C, M)$. The reasoning is exactly the same, except that we need $(C, M)$ to be preferred to $(M, O)$ :

$$
W_{h}(C, M)+W_{f}(M) \geq W_{h}(M, O)+W_{f}(O) .
$$

As in Case 3, this is possible only if $W_{h}(C, M) \geq W_{h}(M, O)$, in which case we have $S E=$ $W_{h}(C, M)-W_{h}(M, O)$, so that this case obtains if and only if $c_{h} \leq c^{*}(1-\rho(O)), c_{f} \geq c^{*}$, and $c_{f} \leq S E+c^{*}$. This set of parameters is non-empty, as shown on Fig. 3 .

- Case 7: $(O, M) \rightarrow(O, O)$. We need to show under which conditions $(O, O)$ is optimal for the 
supranational supervisor, knowing that $\left(d_{h}^{*}, d_{f}^{*}\right)=(O, M)$. Decision pairs $(C, M)$ and $(M, M)$ are dominated by $(O, M)$. Thus, we only need to check that the supranational supervisor prefers $(O, O)$ to $(O, M)$ and to $(M, O)$. Since $d_{h}^{*}=O$ we have $W_{h}(O, M) \geq W_{h}(C, M)$ so that $c_{h} \geq c^{*}\left(1-\rho_{b}(M)\right)$, which implies $c_{h} \geq c^{*}(1-\rho(O))$ and thus $W_{h}(O, O) \geq W_{h}(M, O)$. Hence, the supranational supervisor necessarily prefers $(O, O)$ to $(M, O)$. The last thing to check is that $(O, O)$ is preferred to $(O, M)$ :

$$
W_{h}(O, O)+W_{f}(O) \geq W_{h}(O, M)+W_{f}(M)
$$

Since $W_{h}(C, M) \leq W_{h}(O, M)$, we have $\eta_{M}=0$ and $S E=W_{h}(O, M)-W_{h}(O, O)$. Thus, this case obtains if and only if $c_{h} \geq c^{*}(1-\rho(O)), c_{f} \leq c^{*}$, and $S E \leq c_{f}-c^{*}$. In particular, these inequalities imply that $S E \leq 0$. This set of parameters is non-empty, as shown on Fig. 3 .

- Case 11: $(C, M) \rightarrow(O, O)$. Decisions pairs $(O, M)$ and $(M, M)$ are dominated by $(C, M)$, so that we only need to check that $(O, O)$ dominates $(C, M)$ and $(M, O)$. $(O, O)$ dominates $(M, O)$ if and only if $c_{h} \geq c^{*}(1-\rho(O))$, and $(O, O)$ dominates $(C, M)$ if and only if:

$$
W_{h}(O, O)+W_{f}(O) \geq W_{h}(C, M)+W_{f}(M)
$$

As $d_{h}^{*}=C$ we have $S E=W_{h}(C, M)-W_{h}(O, O)$ so that this condition is equivalent to $S E \leq c_{f}-c^{*}$. Thus, this case obtains if and only if $c_{h} \in\left(c^{*}\left[1-\rho_{g}(M)\right], c^{*}\left[1-\rho_{b}(M)\right]\right], c_{f} \leq c^{*}$, and $S E \leq c_{f}-c^{*}$. In particular, these inequalities imply that $S E \leq 0$. This set of parameters is non-empty, as shown on Fig. 3.

\section{A.6 Proof of Corollary 2}

Using Proposition 3, to prove the Corollary it is sufficient to show that the MNB's profits for different supervisory decisions can be ranked as follows:

$$
\Pi(S, C, M)<\Pi(S, O, M)<\Pi(S, M, O)<\Pi(S, O, O)
$$

In general, the MNB will obtain a positive profit if and only if the home unit is successful. The profit is then equal to the value of residual assets in the home unit, plus the value of residual assets in the foreign unit.

Since in all cases except $(C, M)$ the payoff from the home unit is independent from what happens 
in the foreign unit, we easily obtain:

$$
\begin{aligned}
\Pi(S, O, M) & =\rho(O)+[\theta+(1-\theta) p] \rho(M) \\
\Pi(S, M, O) & =\rho(M)+\rho(O) \\
\Pi(S, O, O) & =\rho(O)+[\theta+(1-\theta) p] \rho(O) .
\end{aligned}
$$

The case $(C, M)$ is more complicated, as now the payoff from the home unit depends on what happens in the foreign unit. With probability $\theta$, the foreign unit has good assets, and the home unit is not monitored. Then the value of residual assets in the home unit is $\rho(O)$, and in addition the MNB obtains a payoff $\rho_{g}(M)$ from the foreign unit if the home unit is successful, which happens with probability $[\theta+(1-\theta) p]$. With probability $1-\theta$, the foreign unit has bad assets and the home unit is monitored. The value of residual assets in the home unit is $\rho(M)$, the MNB makes a positive profit with probability 1 , and obtains an expected $\rho_{b}(M)$ from the foreign unit. Summing up:

$$
\begin{aligned}
\Pi(S, C, M) & =\theta \rho(O)+(1-\theta) \rho(M)+\theta[\theta+(1-\theta) p] \rho_{g}(M)+(1-\theta) \rho_{b}(M) \\
& =\theta \rho(O)+(1-\theta) \rho(M)+[\theta+(1-\theta) p] \rho(M)+(1-\theta)^{2}(1-p) \rho_{b}(M) .
\end{aligned}
$$

We can now compare these different quantities. Recalling that $\rho(M)=\theta \rho_{g}(M)+(1-\theta) \rho_{b}(M)$ and $\rho(O)-\rho(M)=c^{*}$, we have:

$$
\begin{aligned}
\Pi(S, O, M)>\Pi(S, C, M) & \Leftrightarrow(1-\theta)(\rho(O)-\rho(M))-(1-\theta)^{2}(1-p) \rho_{b}(M)>0 \\
& \Leftrightarrow(1-\theta) c^{*}\left(1-\rho_{b}(M)\right)>0 \\
\Pi(S, M, O)>\Pi(S, O, M) & \Leftrightarrow(1-\theta)(1-p) \rho(M)>0 \\
\Pi(S, O, O)>\Pi(S, M, O) & \Leftrightarrow \rho(O)-\rho(M)+-(1-\theta)(1-p) \rho(O)>0 \\
& \Leftrightarrow c^{*}(1-\rho(O))>0,
\end{aligned}
$$

which shows the desired inequalities and concludes the proof. 


\section{A.7 Proof of Proposition 4}

Case (i): Supranational supervision leads to a switch from a subsidiary structure to a branch structure if and only if:

$$
\begin{aligned}
\Pi\left(S, d_{h}^{*}, d_{f}^{*}\right)-C^{S} & \geq \Pi\left(B, d_{h}^{b}, d_{f}^{b}\right)-C^{B} \\
\Pi\left(S, d_{h}^{*}, d_{f}^{*}\right)-C^{S} & \geq \Pi\left(A, d_{h}^{a}\right) \\
\Pi\left(S, d_{h}^{* *}, d_{f}^{* *}\right)-C^{S} & \leq \Pi\left(B, d_{h}^{b}, d_{f}^{b}\right)-C^{B} \\
\Pi\left(B, d_{h}^{b}, d_{f}^{b}\right)-C^{B} & \geq \Pi\left(A, d_{h}^{a}\right) .
\end{aligned}
$$

From (A.28) and (A.30) we deduce that we necessarily have $\Pi\left(S, d_{h}^{*}, d_{f}^{*}\right) \geq \Pi\left(S, d_{h}^{* *}, d_{f}^{* *}\right)$. According to Corollary 2, this is possible only if $c_{f}>c^{*}$. Then, to satisfy all the four inequalities simultaneously, one can for instance pick $C^{S}$ and $C^{B}$ such that:

$$
\begin{aligned}
C^{S} & =\Pi\left(S, d_{h}^{* *}, d_{f}^{* *}\right)-\Pi\left(A, d_{h}^{a}\right) \\
C^{B} & =\Pi\left(B, d_{h}^{b}, d_{f}^{b}\right)-\Pi\left(A, d_{h}^{a}\right)+\frac{\Pi\left(S, d_{h}^{* *}, d_{f}^{* *}\right)-\Pi\left(S, d_{h}^{*}, d_{f}^{*}\right)}{2} .
\end{aligned}
$$

Similarly, for a switch from a subsidiary structure to a stand-alone bank we will need (A.29) and

$\Pi\left(S, d_{h}^{* *}, d_{f}^{* *}\right)-C^{S} \leq \Pi\left(A, d_{h}^{a}\right)$, which implies again $\Pi\left(S, d_{h}^{*}, d_{f}^{*}\right) \geq \Pi\left(S, d_{h}^{* *}, d_{f}^{* *}\right)$ and thus $c_{f}>c^{*}$. One can again easily build values of $C^{S}$ and $C^{B}$ such that this case obtains.

Case (ii): Supranational supervision leads to a switch from a branch structure to a subsidiary structure if and only if:

$$
\begin{aligned}
\Pi\left(B, d_{h}^{b}, d_{f}^{b}\right)-C^{B} & \geq \Pi\left(S, d_{h}^{*}, d_{f}^{*}\right)-C^{S} \\
\Pi\left(B, d_{h}^{b}, d_{f}^{b}\right)-C^{B} & \geq \Pi\left(A, d_{h}^{a}\right) . \\
\Pi\left(S, d_{h}^{* *}, d_{f}^{* *}\right)-C^{S} & \geq \Pi\left(B, d_{h}^{b}, d_{f}^{b}\right)-C^{B} \\
\Pi\left(S, d_{h}^{* *}, d_{f}^{* *}\right)-C^{S} & \geq \Pi\left(A, d_{h}^{a}\right) .
\end{aligned}
$$

Combining (A.34) and (A.36) gives $\Pi\left(S, d_{h}^{* *}, d_{f}^{* *}\right)>\Pi\left(S, d_{h}^{*}, d_{f}^{*}\right)$, which using Corollary 2 is possible only if $c_{f} \leq c^{*}$. Then, to satisfy all the four inequalities simultaneously, one can for instance pick 
$C^{S}$ and $C^{B}$ such that:

$$
\begin{aligned}
C^{B} & =\Pi\left(B, d_{h}^{b}, d_{f}^{b}\right)-\Pi\left(A, d_{h}^{a}\right) \\
C^{S} & =\frac{\Pi\left(S, d_{h}^{* *}, d_{f}^{* *}\right)+\Pi\left(S, d_{h}^{* *}, d_{f}^{* *}\right)}{2}-\Pi\left(A, d_{h}^{a}\right) .
\end{aligned}
$$

Similarly, for a switch from a stand-alone bank to a subsidiary structure we will need (A.37) and

$\Pi\left(S, d_{h}^{*}, d_{f}^{*}\right)-C^{S} \leq \Pi\left(A, d_{h}^{a}\right)$, which implies $\Pi\left(S, d_{h}^{*}, d_{f}^{*}\right) \leq \Pi\left(S, d_{h}^{* *}, d_{f}^{* *}\right)$ and thus $c_{f} \leq c^{*}$. One can again easily build values of $C^{S}$ and $C^{B}$ such that this case obtains.

\section{A.8 Proof of Corollaries 3, 4, 5, and 6}

The proofs of Corollaries 3, 4, and 5 are in the Online Appendix B.3, B.4, and B.5, respectively. Corollary 6 is proven in the main text.

\section{References}

ACharya, V. V. (2003): "Is the International Convergence of Capital Adequacy Regulation Desirable?," Journal of Finance, 58(6), 2745-2782. 5

Agarwal, S., D. Lucca, A. Seru, and F. Trebbi (2014): "Inconsistent Regulators: Evidence from Banking," Quarterly Journal of Economics, 129(2). 5, 11

Aiyar, S., C. W. Calomiris, And T. Wieladek (2014): "Does Macro-Prudential Regulation Leak? Evidence from a UK Policy Experiment," Journal of Money, Credit and Banking, 46(s1), 181-214. 6

Allen, F., T. Beck, E. Carletti, P. R. Lane, D. Schoenmaker, and W. Wagner (2011): CrossBorder Banking in Europe: Implications for Financial Stability and Macroeconomic Policies. Centre for Economic Policy Research, London. 1

Banal-Estanol, A., M. Ottaviani, and A. Winton (2013): "The Flip Side of Financial Synergies: Coinsurance Versus Risk Contamination," The Review of Financial Studies, 26(12), 3142-3181. 21

Barth, J. R., G. Caprio, and R. Levine (2013): "Bank regulation and supervision in 180 countries from 1999 to 2011," Journal of Financial Economic Policy, 5(2), 111-219. 22

Beck, T., C. Silva-Buston, and W. Wagner (2018): "The Economics of Supranational Bank Supervision," CEPR Discussion Papers 12764, C.E.P.R. Discussion Papers. 6

Beck, T., R. Todorov, and W. Wagner (2013): "Supervising Cross-border Banks: Theory, Evidence and Policy," Economic Policy, 28(73). 1, 5

Beck, T., And W. Wagner (2016): "Supranational Supervision - How Much and for Whom?," International Journal of Central Banking, 12(2), 221-268. 6

Bolton, P., And M. Oenmke (2016): "Bank Resolution and the Resolution of Global Banks," Working paper. 6

Bonfim, D., And J. Santos (2017): "The importance of deposit insurance credibility," Working paper. 27 
Calzolari, G., and G. Loranth (2003): "On the Regulation of Multinational Banks," in Antitrust, Regulation and Competition, ed. by M. Baldassarri, and L. Lambertini. Palgrave Macmillan. 5

(2011): "Regulation of Multinational Banks: A Theoretical Inquiry," Journal of Financial Intermediation, 20(2). 5

Carbo-Valverde, S., E. J. Kane, and F. Rodriguez-Fernandez (2012): "Regulatory Arbitrage in Cross-Border Banking Mergers within the EU," Journal of Money, Credit and Banking, 44(8), 1609-1629. 22,24

Carletti, E., G. Dell'Ariccia, And R. Marquez (2016): "Supervisory Incentives in a Banking Union," Working paper. 6

Cerutti, E., G. Dell'Ariccia, and M. S. Martinez Peria (2007): "How Banks Go Abroad: Branches or Subsidiaries?," Journal of Banking \& Finance, 31(6), 1669-1692. 5, 10, 22

Cerutti, E. M., A. Ilyina, Y. Makarova, And C. Schmieder (2010): "Bankers Without Borders? Implications of Ring-Fencing for European Cross-Border Banks," IMF Working Papers 10/247, International Monetary Fund. 25

Claessens, S., And N. Van Horen (2013): "Impact of Foreign Banks," Journal of Financial Perspectives, 1(1), 29-42. 1

Colliard, J.-E. (2014): "Monitoring the Supervisors: Optimal Regulatory Architecture in a Banking Union," Working paper. 6

Dahlby, B. (2008): The Marginal Cost of Public Funds. MIT Press, Cambridge (Mass.). 8

Dalen, D. M., And T. E. Olsen (2003): "Regulatory Competition and Multinational Banking," Working paper. 5

Dell'Ariccia, G., And R. Marquez (2006): "Competition Among Regulators and Credit Market Integration," Journal of Financial Economics, 79(2), 401-430. 5

(2010): "Risk and the Corporate Structure of Banks," Journal of Finance, 65(3), 1075-1096. 5

Demirguc-Kunt, A., E. Kane, And L. Laeven (2014): "Deposit Insurance Database," IMF Working Papers 14/118, International Monetary Fund. 10, 26

Dewatripont, M., and J. Tirole (1994): The Prudential Regulation of Banks. MiT Press, Cambridge (Mass.). 10

Eisenbach, T. M., D. O. Lucca, And R. M. Townsend (2016): "The economics of bank supervision," Staff Reports 769, Federal Reserve Bank of New York. 3, 22

Faia, E., And B. Weder di Mauro (2016): "Cross-Border Resolution of Global Banks: Bail in under Single Point of Entry versus Multiple Points of Entry," Working paper. 6

Fiechter, J., I. Otker, A. Ilyina, M. Hsu, A. O. Santos, And J. Surti (2011): "Subsidiaries or Branches; Does One Size Fit All?," IMF Staff Discussion Notes 11/04, International Monetary Fund. 10, 22

Fiordelisi, F., O. Ricci, And F. S. Stentella Lopes (2017): "The Unintended Consequences of the Launch of the Single Supervisory Mechanism in Europe," Journal of Financial and Quantitative Analysis, 52(06), 2809-2836. 22, 24

Focarelli, D., And A. F. Pozzolo (2005): "Where Do Banks Expand Abroad? An Empirical Analysis," Journal of Business, 78(6), 2435-2464. 5 
Haas, R. D., Y. Korniyenko, A. Pivovarsky, and T. Tsankova (2015): "Taming the herd? Foreign banks, the Vienna Initiative and crisis transmission," Journal of Financial Intermediation, 24(3), 325 355. 26

HaRR, T., AND T. RøNDE (2004): "Regulation of Banking Groups," Working paper. 5

Hirtle, B., A. Kovner, And M. Plosser (2016): "The impact of supervision on bank performance," Staff Reports 768, Federal Reserve Bank of New York. 7

Holthausen, C., And T. Rønde (2004): "Cooperation in International Banking Supervision," Working paper. 5,11

Horváth, B. L., And W. Wagner (2017): "The Disturbing Interaction between Countercyclical Capital Requirements and Systemic Risk," Review of Finance, 21(4), 1485-1511. 6

Kahn, C., And A. Winton (2004): "Moral Hazard and Optimal Subsidiary Structure for Financial Institutions," Journal of Finance, 59(6), 2531-2575. 5

Karolyi, G. A., And A. G. Taboada (2015): "Regulatory Arbitrage and Cross-Border Bank Acquisitions," Journal of Finance, 70(6), 2395-2450. 24

Loranth, G., And A. D. Morrison (2007): "Deposit Insurance, Capital Regulation and Financial Contagion in Multinational Banks," Journal of Business, Finance and Accounting, 34(5-6). 5

Luciano, E., AND C. WihlBorg (2018): "Financial synergies and systemic risk in the organization of bank affiliates," Journal of Banking \&5 Finance, 88, 208 - 224. 5

Ongena, S., A. Popov, And G. F. Udell (2013): "When the cat's away the mice will play": Does regulation at home affect bank risk-taking abroad?," Journal of Financial Economics, 108(3), 727-750. 24

Peltzman, S. (1976): "Toward a More General Theory of Regulation," The Journal of Law and Economics, 19(2), 211-240. 6

Repullo, R. (2001): "A Model of Takeovers of Foreign Banks," Spanish Economic Review, 3(1), 1-21. 11

Rezende, M. (2011): "How Do Joint Supervisors Examine Financial Institutions? The Case of State Banks," in Handbook of Central Banking, Financial Regulation and Supervision after the Financial Crisis, ed. by S. Eijffinger, and D. Masciandaro, pp. 531-572. Edward Elgar. 5

Rochet, J.-C. (1992): "Capital Requirements and the Behaviour of Commercial Banks," European Economic Review, 36(5), 1137-1170. 28

Schoenmaker, D., And P. Huttl (2015): "Should the Outs Join the Banking Union?," European Economy: Banks, Regulation, and the Real Sector, 1(3), 89-112. 1 


\section{B Supplementary Appendix for "Multinational Banks and Supra- national Supervision"}

For online publication only.

\section{B.1 End of the proof of Proposition 2}

First, consider again decision $C^{\prime}$, which can only be combined with decision $M$. Since $c_{h} \leq c_{f}$, the only relevant decision pair to consider is $\left(M, C^{\prime}\right)$.

$$
\begin{aligned}
W_{b}\left(M, C^{\prime}\right)= & (1-\theta)(1-\theta)(1-p)(r-2) \\
& -c_{h}-\theta c_{f}
\end{aligned}
$$

In order for $W_{b}\left(M, C^{\prime}\right)$ to be optimal, it should give a higher payoff than $W_{b}(M, O)$ and $W_{b}(M, O)$. These conditions boil down to:

$$
c^{*}\left(1-\rho_{b}(M)\right) \leq c_{f} \leq c^{*}\left(1-\rho_{g}(M)\right)
$$

However, as $\rho_{b}(M)<\rho_{g}(M)$, we reach a contradiction. $W_{b}\left(M, C^{\prime}\right)$ will always be dominated either by decisions $(M, O)$ or by $(M, M)$.

Second, consider a new decision $M^{\prime}$ : the branch supervisor monitors the home unit, does not intervene when the assets are bad, but uses this information to monitor the foreign unit. The strategy pair $\left(M^{\prime}, C\right)$ thus allows to monitor the foreign unit only when it is most useful, but without reducing the value of the home unit's assets. $W_{b}\left(M^{\prime}, C\right)$ can be computed by replacing in the expression of $W_{b}(M, C)$ :

$$
\begin{aligned}
W_{b}\left(M^{\prime}, C\right)= & \theta(1-\theta)(1-p)(R-2)+(1-\theta)(1-p)(\theta R+(1-\theta) r-2)+ \\
& -c_{h}-(1-\theta) c_{f}
\end{aligned}
$$

With simple calculations we obtain

$$
W_{b}(M, O)-W_{b}\left(M^{\prime}, C\right)=(1-p)(2-R)(1-\theta) \theta+(1-\theta) c_{f} \geq 0
$$


and decisions $\left(M^{\prime}, C\right)$ can never be optimal.

Finally, decisions $\left(M^{\prime}, C^{\prime}\right)$ are dominated by $\left(M^{\prime}, C\right)$ because, if anything, $d_{h}=M^{\prime}$ is meant to monitor the foreign unit when it is most useful, so that $d_{f}=C$ would be better than $d_{f}=C^{\prime}$.

\section{B.2 End of the proof of Proposition 3}

To conclude the proof, we need to show that cases 10 and 11 can never obtain, and that the strategies $d_{f} \in\left\{C, C^{\prime}, M^{\prime}\right\}$ cannot be optimal under supranational supervision.

- Case 10: $(M, M) \rightarrow(M, O)$. This case is impossible. We need $(M, O)$ to dominate $(M, M)$ for the supranational supervisor, which writes:

$$
W_{h}(M, O)+W_{f}(O) \geq W_{h}(M, M)+W_{f}(M) .
$$

Since $W_{h}(M, O)=W_{h}(M, M)=-c_{h}$, we need $W_{f}(O) \geq W_{f}(M)$, which contradicts the fact that $d_{f}^{*}=M$, so that this case cannot obtain.

- Case 12: $(C, M) \rightarrow(M, O)$. This case is impossible. We need to check that $(M, O)$ dominates $(C, M)$, which gives:

$$
W_{h}(M, O)+W_{f}(O) \geq W_{h}(C, M)+W_{f}(M) .
$$

As $d_{f}^{*}=M$, we have $W_{f}(M) \geq W_{f}(O)$ so we need $W_{h}(M, O) \geq W_{h}(C, M)$. However, since $d_{h}^{*}=C$ we have $W_{h}(C, M) \geq W_{h}(M, M)=W_{h}(M, O)$, so this case cannot obtain.

We can now consider the additional strategies $d_{f} \in\left\{C, C^{\prime}, M^{\prime}\right\}$, which cannot obtain under national supervision. Note that due to Lemma 1 we only need to show that the supranational supervisor never uses these strategies in the foreign unit. In particular, the Lemma ensures that if $d_{f} \in\{M, O\}$ then $d_{h} \in\left\{C^{\prime}, M^{\prime}\right\}$ cannot be optimal for the supranational supervisor.

- $d_{f}=C$ is not optimal: it is easy to show that $(M, C)$ dominates $\left(M^{\prime}, C\right)$, so we focus on the former. We have:

$$
\begin{aligned}
W_{h}(M, C) & =-c_{h} \\
W_{f}(C) & =\theta W_{f}(O)+(1-\theta) W_{f}(M) .
\end{aligned}
$$

Note that $W_{h}(M, C)=W_{h}(M, M)$, so that $(M, C)$ dominates $(M, M)$ if and only if $W_{h}(M, C)+$ $W_{f}(C) \geq W_{h}(M, M)+W_{f}(M)$, which is equivalent to $W_{f}(O) \geq W_{f}(M)$. However, if this is the case we also have $W_{h}(M, O)+W_{f}(O) \geq W_{h}(M, C)+W_{f}(C)$, because $W_{h}(M, O) \geq W_{h}(M, C)=$ 
$W_{h}(M, M)$ and $W_{f}(O) \geq W_{f}(M) \Rightarrow W_{f}(O) \geq W_{f}(C)$. Thus, $(M, C)$ is necessarily dominated either by $(M, M)$ or by $(M, O)$, and $d_{f}=C$ can never be optimal.

- $d_{f}=M^{\prime}$ is not optimal: the only point of choosing $M^{\prime}$ rather than $O$ is to have $d_{h}=C$, so we consider the pair $\left(C, M^{\prime}\right)$. We have $W_{f}\left(M^{\prime}\right)=W_{f}(O)-c_{f}$ and:

$$
W_{h}\left(C, M^{\prime}\right)=\theta\left[(1-\theta)(1-p)\left[-1+\rho_{g}(O)\right]\right]-(1-\theta) c_{h} .
$$

For $\left(C, M^{\prime}\right)$ to be optimal we need in particular $W_{h}\left(C, M^{\prime}\right)+W_{f}\left(M^{\prime}\right) \geq W_{h}(C, M)+W_{f}(M)$, which gives:

$$
\theta(1-\theta)(1-p)\left[\rho_{g}(O)-\rho_{g}(M)\right] \geq W_{f}(M)-W_{f}(O)+c_{f}
$$

Since $\rho_{g}(O)=\rho_{g}(M)$, we need $W_{f}(O)-W_{f}(M) \geq c_{f}$, which is false since $w_{f}(O)-W_{f}(M)=c_{f}-c^{*}$. Hence, $\left(C, M^{\prime}\right)$ is always dominated by $(C, M)$ and $d_{f}=M^{\prime}$ can never be optimal.

- $d_{f}=C^{\prime}$ is not optimal: This decision makes sense only if the supranational supervisor chooses $\left(M, C^{\prime}\right)$, in which case we have:

$$
\begin{aligned}
W_{f}\left(C^{\prime}\right) & =\theta W_{f}(M)+(1-\theta) W_{f}(O) \\
W_{h}\left(M, C^{\prime}\right) & =-c_{h} .
\end{aligned}
$$

Since $W_{h}\left(M, C^{\prime}\right)=W_{h}(M, O)=W_{h}(M, M)$, it is clear that we cannot simultaneously have $W_{h}\left(M, C^{\prime}\right)+W_{f}\left(C^{\prime}\right)>W_{h}(M, M)+W_{f}(M)$ and $W_{h}\left(M, C^{\prime}\right)+W_{f}\left(C^{\prime}\right)>W_{h}(M, O)+W_{f}(O)$. Hence, $\left(M, C^{\prime}\right)$ is always dominated by another strategy, and $d_{f}=C^{\prime}$ cannot be optimal.

\section{B.3 Proof of Corollary 3}

Case (i). We know from Proposition 3 that supranational supervision leads to more monitoring, and this decreases the MNB's profit (Corollary 2). Since the supranational supervisor maximizes the joint payoffs to the national supervisors and deposit insurance funds, the total payoff increases by definition.

The last point to study is total welfare. Obviously for a large enough $\lambda$ the decrease in total public costs will dominate the decrease in the MNB's profits, and total welfare will increase. Conversely, if $\lambda=0$ then total welfare is simply the total value of the MNB's assets minus the MNB's operating costs, minus supervision costs. The total value of the assets in unit $i$ is $[\theta+(1-\theta) p] R$ if $d_{i}=O, \theta R+(1-\theta) r$ if $d_{i}=M$, and $\theta[\theta+(1-\theta) p] R+(1-\theta)[\theta R+(1-\theta) r]$ if $d_{i}=C$. Since $r=p R$, 
these three quantities are equal: monitoring keeps the total value of the assets unchanged. Thus, when $\lambda=0$ the only impact of supranational supervision is an increase in monitoring costs, which reduces total welfare. Thus, there exists a positive level $\bar{\lambda}_{1}>0$ such that supranational supervision increases welfare if and only if $\lambda \geq \bar{\lambda}_{1}$.

Case (ii). Now supranational supervision leads to less monitoring, which increases the MNB's profit. However, it is still the case that supranational supervision necessarily decreases the total public costs, for the same reason as in case (i). Since now supranational supervision benefits both the MNB and the public sector, total welfare necessarily increases, for any value of $\lambda$.

\section{B.4 Proof of Corollary 4}

Case (i). If the MNB changes its structure from subsidiary to branch, we necessarily have $\Pi\left(S, d_{h}^{*}, d_{f}^{*}\right)-$ $C^{S} \geq \Pi\left(B, d_{h}^{b}, d_{f}^{b}\right)-C^{B}$, because otherwise the MNB would have preferred the branch structure under national supervision. So the MNB's profit decreases. For the impact on total public costs, note that with a branch structure the home supervisor can always replicate the decisions of the subsidiary under national supervision and choose $\left(d_{h}^{b}, d_{f}^{b}\right)=\left(d_{h}^{*}, d_{f}^{*}\right)$. By doing so, the total monitoring costs are the same as under national supervision, but the total losses to the deposit insurance are lower given the liability structure of the branch. The sum of the losses to the deposit insurance funds and monitoring costs is thus lower in the branch case when $\left(d_{h}^{b}, d_{f}^{b}\right)=\left(d_{h}^{*}, d_{f}^{*}\right)$, and a fortiori for the optimal supervisory decisions of the branch supervisor. This shows that supranational supervision, by inducing a switch from subsidiary to branch, lower the total public costs.

Finally, we analyze total welfare. Consider the case in which $\lambda=0$, and $C^{B}=C^{S}$. As argued in the proof of Corollary 4, in this case the only part of total welfare that is affected by supervisory decisions is monitoring costs. As shown in Corollary 1, the branch is less monitored than the subsidiary under national supervision, so that monitoring costs decrease after the switch to a branch structure. Thus, total welfare necessarily increases with supranational supervision. If $\lambda>0$, we are just putting more weight on the public costs, which are reduced by supranational supervision, and less on the MNB's profit. So the impact on total welfare is a fortiori positive. If $C^{B} \leq C^{S}$, the switch to a branch also reduces operating costs, so that again the impact on total welfare is necessarily positive.

Case (ii). Recall that the branch is unaffected by supranational supervision, so if the MNB switches from a branch to a subsidiary structure it is necessarily the case that $\Pi\left(S, d_{h}^{* *}, d_{f}^{* *}\right)-C^{S} \geq$ $\Pi\left(B, d_{h}^{b}, d_{f}^{b}\right)-C^{B}$. Thus, the MNB's profit increases. For the impact on total public costs, note 
that there is no externality in the branch case (only one supervisor), so the supranational supervisor would take exactly the same decision in the branch as the home supervisor. However, for any given decision the total public costs are larger with a subsidiary than with a branch, so necessarily total public costs increase with the switch from branch under national supervision to subsidiary under supranational supervision.

For total welfare, again in the case $\lambda=0$ and $C^{B}=C^{S}$ it is clear that total welfare decreases under supranational supervision due to larger monitoring costs. This is a fortiori true if $\lambda>0$ because we put more weight on the public sector, which is negatively affected by supranational supervision, and if $C^{B} \leq C^{S}$, because the MNB chooses a structure with higher operating costs.

\section{B.5 Proof of Corollary 5}

The reasoning is similar to the proof of Corollary 4 .

Case (i). It is clear that when the MNB shuts down its foreign unit the MNB's profit decreases,

$$
\Pi\left(S, d_{h}^{*}, d_{f}^{*}\right)-C^{S} \geq \Pi\left(A, d_{h}^{a}\right) \geq \max \left\{\Pi\left(S, d_{h}^{* *}, d_{f}^{* *}\right)-C^{S}, \Pi\left(B, d_{h}^{b}, d_{f}^{b}\right)-C^{B}\right\}
$$

otherwise the MNB would not have opened the foreign unit under national supervision. Consider the total public costs. Under Case (i) we have $d_{f}^{*}=O$, so that $d_{h}^{*} \in\{M, O\}$. If $d_{h}^{*}=M$, then after the switch to stand-alone we necessarily have $d_{h}^{a}=M$ as well (because the loss of foreign residual assets reinforces the incentives to monitor the home unit). Hence, the total monitoring costs are equal to $c_{h}$ in both cases. The total losses to the deposit insurance funds are equal to $(1-\theta)(1-p)$ under national supervision (subsidiary) and to 0 under supranational supervision (stand-alone). Hence, total public costs are lower under supranational supervision. If $d_{h}^{*}=O$ instead, since the supranational supervisor chooses $d_{h}^{a}$ so as to minimize total public costs, these public costs are lower than or equal to the costs obtained when $d_{h}^{a}=O$. If $d_{h}^{*}=d_{h}^{a}=O$ the monitoring costs are not affected by supranational supervision, and total losses to the deposit insurance funds decrease from $(1-\theta)(1-p)+(1-\theta)(1-p)[1-\rho(O)]$ to $(1-\theta)(1-p)$. In all cases, supranational supervision thus reduces total public costs.

Because of this last result, supranational supervision necessarily increases total welfare if $\lambda$ is large enough. When $\lambda=0$ instead, we only need to consider the total value of the MNB's assets and the monitoring costs and the organizational cost $C^{S}$. The switch to a stand-alone reduces the total value of the MNB's assets due to (H1). Monitoring costs in the foreign unit do not decrease 
because Case (i) implies that $d_{f}^{*}=O$, and monitoring costs in the home unit do not decrease either, since the stand-alone cannot be less monitored than the home unit of a subsidiary. Hence, total welfare necessarily decreases when $\lambda=0$. Given that total welfare is linear in $\lambda$, there exists a value $\bar{\lambda}_{2}$ as described in the Corollary.

Case (ii). The reasoning is entirely symmetric. 